\title{
PSMD1 and PSMD2 regulate HepG2 cell proliferation and apoptosis via modulating cellular lipid droplet metabolism
}

\author{
Yanjie $\operatorname{Tan}^{1}$, Yi Jin ${ }^{1}$, Xiang $\mathrm{Wu}^{1}$ and Zhuqing Ren ${ }^{1,2^{*}}$ (])
}

\begin{abstract}
Background: Obesity and nonalcoholic steatohepatitis (NASH) are well-known risk factors of hepatocellular carcinoma (HCC). The lipid-rich environment enhances the proliferation and metastasis abilities of tumor cells. Previous studies showed the effect of the ubiquitin-proteasome system (UPS) on tumor cell proliferation. However, the underlying mechanism of UPS in regulating the proliferation of lipid-rich tumor cells is not totally clear.

Results: Here, we identify two proteasome 26S subunits, non-ATPase 1 and 2 (PSMD1 and PSMD2), which regulate HepG2 cells proliferation via modulating cellular lipid metabolism. Briefly, the knockdown of PSMD1 and/or PSMD2 decreases the formation of cellular lipid droplets, the provider of the energy and membrane components for tumor cell proliferation. Mechanically, PSMD1 and PSMD2 regulate the expression of genes related to de novo lipid synthesis via p38-JNK and AKT signaling. Moreover, the high expression of PSMD1 and PSMD2 is significantly correlated with poor prognosis of HCC.
\end{abstract}

Conclusion: We demonstrate that PSMD1 and PSMD2 promote the proliferation of HepG2 cells via facilitating cellular lipid droplet accumulation. This study provides a potential therapeutic strategy for the treatment of lipid-rich tumors.

Keywords: PSMD1, PSMD2, Lipid droplet, Cell proliferation

\section{Background}

Hepatocellular carcinoma ( $\mathrm{HCC})$ is one of the most frequent causes of cancer-related deaths worldwide [1]. The chronic liver damage and inflammation caused by chronic hepatitis $\mathrm{B}$ virus or hepatitis $\mathrm{C}$ virus infections are common reason for $\mathrm{HCC}$ development. However, the incidence of nonviral HCC is rapidly increasing, especially in developed countries. Non-alcoholic fatty liver disease (NAFLD) and non-alcoholic steatohepatitis (NASH), which are usually enhanced by obesity, are well-known risk factors of HCC $[2,3]$. Patients with obesity and NAFLD/NASH show an increased intake of

\footnotetext{
*Correspondence: renzq@mail.hzau.edu.cn

${ }^{1}$ Key Laboratory of Swine Genetics and Breeding of Ministry of Agriculture \& Key Laboratory of Agriculture Animal Genetics, Breeding and Reproduction of Ministry of Education, College of Animal Science, Huazhong Agricultural University, Wuhan 430070, Hubei, People's Republic of China

Full list of author information is available at the end of the article
}

dietary fatty acids (FAs), and meanwhile, insulin resistance enhances lipolysis of adipose tissue, which causes an increased exogenous FA supply and results in the development of a "lipid-rich" environment for hepatocytes. The lipid-rich environment is considered to promote the proliferation and metastasis of tumor cells [4-6]. Compared to normal cells, the tumor cells usually uptake larger amount of lipids, accompanied by enhanced lipogenesis and cholesterol $(\mathrm{CH})$ production and increased fatty acid (FA) $\beta$-oxidation $[7,8]$. Furthermore, FA synthetases such as FASN and ACS play an important role in tumor cell proliferation and tumorigenicity $[9,10]$. Lipids are required for the proliferation process. For example, the ovarian tumor cells can obtain lipids from the adipocytes grown in coculture experiments [11]. Besides enhanced lipid uptake, tumor cells often accumulate a larger amount of cellular lipid droplets (LDs) compared to normal cells [12], which might promote the proliferation process, thereby favoring the development of a more 
aggressive phenotype [13]. Moreover, evidence indicates that a higher level of LDs in cancer cells is associated with higher tumor aggressiveness $[14,15]$. Recently, LDs showed a powerful effect on cellular lipid metabolism, which regulates lipid synthesis, lipolysis, and lipid turnover $[16,17]$. The proteins decorated in the monolayer of phospholipids of LDs control the activities of LDs [1820]. Therefore, the LD-related proteins are involved in the regulation of cellular lipid metabolism.

The ubiquitin-proteasome system (UPS) is a huge and complex system that regulates the degradation of up to $80 \%$ of cellular proteins, consisting of ubiquitin (Ub), Ub-activating enzymes (E1s, two classes, nearly 10 members), Ub-conjugating enzymes (E2s, approximately 40 members), Ub-protein ligases (E3s, more than 600 members), deubiquitinating enzymes (DUBs, roughly 90 members), and the heart of the system, the $26 \mathrm{~S}$ proteasome complex [21-25]. Previous studies showed that UPS is involved in a wide range of biological processes, including cell growth, the cell cycle, DNA metabolism, and signal transduction [26, 27]. The deregulation of UPS or its components results in severe pathological disorders and changes in the expression levels of many tumor promoters and suppressors [21, 28-31]. The $26 \mathrm{~S}$ proteasome is a multi-enzyme complex that responds to the degradation of intracellular proteins in eukaryotic cells [32-34]. PSMD1 and PSMD2 are two subunits of the $19 \mathrm{~S}$ regulatory complex of the $26 \mathrm{~S}$ proteasome [35-38]. Recent studies indicate that knockdown of PSMD1 and/ or PSMD2 is able to suppress tumor cell proliferation [39-41]. Many studies about the proteomes of LDs have found that PSMD1 and PSMD2 are LD-related proteins in several species such as humans, mice, and C. elegans [42-48]. However, the regulatory roles of PSMD1 and PSMD2 in cellular lipid metabolism are unclear.

In the present study, we chose a hepatocellular carcinoma cell line, HepG2, to investigate the roles of PSMD1 and PSMD2 in cell proliferation and cellular lipid metabolism. HepG2 cells were derived from 15-year-old white liver cancer tissue and were utilized in the study about hepatocyte metabolism. Firstly, we showed that the expression levels of PSMD1 and PSMD2 affected cell proliferation and apoptosis. The knockdown of PSMD1 and PSMD2 inhibited cell proliferation and promoted cell apoptosis, and overexpression of PSMD1 and PSMD2 showed the opposite effects. Furthermore, the expression of PSMD1 and PSMD2 affected several proliferation and apoptosis related molecules. Because cellular lipid content is associated with cell proliferation and apoptosis, we further investigated the effects of PSMD1 and PSMD2 expression on cellular lipid metabolism. The knockdown of PSMD1 and PSMD2 decreased the content of cellular lipids. On the contrary, the overexpression of PSMD1 and PSMD2 promoted lipid formation and increased the cellular lipid content. Mechanically, PSMD1 and PSMD2 inhibition suppressed fatty acid and lipid synthesis by downregulating SREBF1 and $P P A R Y$ via ASK-p38-JNK and AKT signaling. Moreover, through bioinformatic analysis, high expression levels of PSMD1 and PSMD2 were significantly correlated with poor prognosis of liver hepatocellular carcinoma. Therefore, the high expression levels of PSMD1 and PSMD2 probably enhanced hepatocellular carcinoma tumor cell proliferation. PSMD1 and PSMD2 could be potential therapeutic targets for this type of tumor.

\section{Materials and methods}

\section{Cell culture and transfection}

HepG2 and Huh7 cells were purchased from the Type Culture Collection of the Chinese Academy of Sciences (Wuhan, China). Cells were cultured with Dulbecco's modified Eagle's medium (DMEM, HyClone, Logan, UT, USA) supplemented with $10 \%$ fetal bovine serum (FBS, AusGeneX, Molendinar, Australia) at $37{ }^{\circ} \mathrm{C}$ in a humidified atmosphere of $5 \% \mathrm{CO}_{2}$. Cells were transfected with Lipo8000 ${ }^{\mathrm{TM}}$ Transfection Reagent (\#C0533, Beyotime, Nanjing, China). HepG2 cells were seeded on the cell slide in a 6-well plate and transfected with the plasmid vector in accordance with the transfection reagent instructions.

\section{Oleic acid treatment}

For oleic acid treatment, a $20 \mathrm{mM}$ oleic acid (LPS free)phosphate buffer saline (PBS) mixture and 20\% FA-free bovine serum albumin (BSA) medium were prepared, and both media were heated in a $70{ }^{\circ} \mathrm{C}$ water bath for $30 \mathrm{~min}$. Finally, the media were mixed. The $10 \mathrm{mM}$ oleic acid-BSA mixture was added to the cell cultural medium at 1:49 (v:v). To identify the best treatment time, a time course was performed. The cells were treated with $200 \mu \mathrm{M}$ oleic acid (OA) for $0,1,2,3,4,5$, and $6 \mathrm{~h}$ respectively, and then were stained by BODIPY to indicate the cellular LDs. The images showed that cellular LDs were able to be observed at $2 \mathrm{~h}$ after OA treatment. Many LDs formed "grape-like" structures at $5 \mathrm{~h}$ after OA treatment, and additionally, the image from the $6 \mathrm{~h}$ treatment showed little difference from the image from the $5 \mathrm{~h}$ treatment (Additional file 1: Fig. S1A). Therefore, the $6 \mathrm{~h}$ treatment was considered to be the best choice for the experiment. The cells that were seeded on the slides or plates were washed 3 times using PBS. One millilitre of 
oleic acid medium was added to the well $(200 \mu \mathrm{M})$, and the cells were cultured for $6 \mathrm{~h}$.

\section{MTT assay}

HepG2 cell proliferation was detected using MTT Cell Proliferation and Cytotoxicity Assay Kit (Beyotime, Nanjing, China). Briefly, cells were seeded at a density of $4 \times 10^{3} /$ well in 96 -well plates $24 \mathrm{~h}$ after transfection. At different time points, $10 \mu \mathrm{L}$ MTT $(5 \mathrm{mg} / \mathrm{mL})$ was added to each well and cells were cultured for another $4 \mathrm{~h}$. Furthermore, $100 \mu \mathrm{L}$ Formazan solution was added into each well and the optical density (OD) at $570 \mathrm{~nm}$ was measured on a microplate reader (PerkinElmer, Germany).

\section{CCK8 assay}

HepG2 and Huh7 cells activity after oleic acid treatment was detected by Cell Counting Kit-8 (CCK8) kit (\#CK04, DOJINDO LABORATORISE, Shanghai, China). Briefly, cells were seeded at a density of $4 \times 10^{3} /$ well in 96-well plates. The cells were treated with $200 \mu \mathrm{M}$ oleic acid for $0 \mathrm{~h}, 6 \mathrm{~h}, 12 \mathrm{~h}$ and $24 \mathrm{~h}$. Then $10 \mu \mathrm{L}$ CCK 8 was added to each well and cells were cultured for another $4 \mathrm{~h}$. The optical density (OD) at $450 \mathrm{~nm}$ was measured on a microplate reader (PerkinElmer, Germany).

\section{Flow cytometric analysis of the cell cycle}

Cells were collected and fixed in $70 \%$ ice-cold ethanol at $4{ }^{\circ} \mathrm{C}$ overnight. Then, the cells were centrifuged and washed with PBS. After incubation with $100 \mu \mathrm{L}$ RNase A $(0.1 \mathrm{mg} / \mathrm{mL})$ for $30 \mathrm{~min}$ at $37{ }^{\circ} \mathrm{C}, 2 \mu \mathrm{L}$ propidium iodide (PI, Sigma-Aldrich, St. Louis, MO, USA) was add to the cells and incubated for another $30 \mathrm{~min}$ at room temperature in the dark. Finally, cell cycle profiling was performed using a FACSCalibur Flow Cytometer (Becton-Dickinson, Franklin Lakes, NJ, USA), and the data were analyzed using ModFit software (Verity Software House).

\section{Cell apoptosis assay}

At $48 \mathrm{~h}$ after transfection, the percentage of apoptotic cells was measured using an Annexin V fluorescein isothiocyanate (FITC) apoptosis detection kit (BD Biosciences, USA) and analyzed by flow cytometry (BD Biosciences, USA) in accordance with the manufacturer's protocol.

\section{5-Ethynyl-2'-deoxyuridine (EdU) assay}

Cells seeded in 12-well plates were cultured to $50 \%$ confluence and then transfected. Forty-eight hours after transfection with siRNAs or overexpression plasmid, the cells were fixed and stained with a BeyoClick ${ }^{\mathrm{TM}}$ EdU Cell Proliferation Kit with Alexa Fluor 594 (Beyotime, China) in accordance with the instructions. A fluorescence microscope (Olympus, Japan) was used to capture three randomly selected fields to visualize the number of EdUpositive cells.

\section{RNA oligonucleotides and plasmid construction}

siRNA oligos against PSMD1 and PSMD2 were obtained from Ribobio (Guangzhou, China). The sequence of the siRNA against the PSMD1 coding region was 5'-GAG AAAGACAGUGACUCGAUGGAAA- $3^{\prime}$, and that of the siRNA against the PSMD2 coding region was $5^{\prime}$ CCCAAGGUGCCUGAUGACAUCUACA-3' ${ }^{\prime}$ [49]. The expression vector used in this study was constructed according to the instructions of a Seamless Cloning Kit (Vazyme Biotech Co., Ltd.). The primers used for plasmid vector construction are listed in Additional file 2: Table S1.

\section{RNA interference and overexpression assay}

The siRNAs targeting PSMD1 and PSMD2 were obtained from Ribobio (Guangzhou, China). Cells were seeded onto 6-well plates in DMEM supplemented with $10 \%$ FBS at $37{ }^{\circ} \mathrm{C}$ in a humidified atmosphere of $5 \% \mathrm{CO}_{2}$. Cells at $70-80 \%$ confluence were transfected with $10 \mu \mathrm{L}$ of siRNA using Lipo8000 ${ }^{\mathrm{TM}}$ Transfection Reagent (\#C0533, Beyotime, Nanjing, China). For the overexpression assay, $4 \mu \mathrm{g}$ of the constructed plasmid was transfected with $10 \mu \mathrm{L}$ of Lipo8000 ${ }^{\mathrm{TM}}$ Transfection Reagent (\#C0533, Beyotime, Nanjing, China). All transfections were performed in triplicate, and the data are presented as the mean \pm standard deviation (SD).

\section{RNA extraction, reverse transcription polymerase chain reaction (RT-PCR), and real-time quantitative $R T-P C R$ (qRT-PCR)}

Total RNA was extracted using TRIzol (Life Technologies Inc., Carlsbad, CA, USA). RNA concentrations were determined using spectrophotometry with a NanoDrop 2000 (Thermo Fisher Scientific). A total of $1 \mu \mathrm{g}$ of RNA was then subjected to reverse transcription to cDNA using a Reverse Transcription Kit (\#R232-01; HiScript II Q Select RT SuperMix for qPCR; Vazyme, Nanjing, China). qRT-PCR was performed with SYBR Green I Real-Time PCR Master Mix (\#Q131-02; AceQ qPCR SYBR Green Master Mix; Vazyme; Nanjing, China) on a LightCycler ${ }^{\circledR} 480$ Real-Time System (Roche) and QuantStudio 6 Flex Real-Time PCR System (ABI, Thermo Fisher, Shanghai, China). The primer sequences used for qRTPCR are listed in Additional file 2: Table S2. GAPDH and $A C T B$, the most frequently used housekeeping genes, were chosen as candidates. Then, the stability of the candidate reference genes was analyzed through standard curve and geNorm methods (Additional file 2: Tables S3, S4). Consequently, GAPDH was chosen as the reference 
standard for normalization. The related method was based on that used in Costantini et al.s study [50]. The relative gene expression was calculated by the $2^{-\Delta \Delta} \mathrm{Ct}$ method, and the Student's $t$ test was used for statistical analysis.

\section{Western blotting}

Western blotting was performed as reported previously [51]. The following antibodies were used: anti-PSMD1 (\#A16420; rabbit polyclonal antibody; ABclonal; 1:1000 dilution), anti-PSMD2 (\#14748-1-AP; rabbit polyclonal antibody; Proteintech; 1:1000 dilution), anti-ASK1 (\#A6274; rabbit polyclonal antibody; ABclonal; 1:2000 dilution), anti- p-ASK1 (\#AP0394; rabbit polyclonal antibody; ABclonal; 1:2000 dilution), anti-AKT (\#A11027; rabbit polyclonal antibody; ABclonal; 1:2000 dilution), anti-p-AKT (\#AP0140; rabbit polyclonal antibody; ABclonal; 1:2000 dilution), anti-p38 (\#A10832; rabbit polyclonal antibody; ABclonal; 1:2000 dilution), antip-p38 (\#AP0297; rabbit polyclonal antibody; ABclonal; 1:2000 dilution), anti-JNK1/2 (\#A11119; rabbit polyclonal antibody; ABclonal; 1:2000 dilution), anti-p-JNK1/2 (\#AP0631; rabbit polyclonal antibody; ABclonal; 1:2000 dilution), anti-GAPDH (Servicebio, Wuhan, China; 1:2000 dilution), anti-Tubulin (Servicebio, Wuhan, China; 1:2000 dilution), HRP-labeled Goat Anti-Rabbit IgG $(\mathrm{H}+\mathrm{L})$ (\#GB23303-1, Servicebio, Wuhan, China), and HRP-labeled Goat Anti-Mouse IgG (H+L) (\#GB23301, Servicebio, Wuhan, China).

\section{Lipid droplet marking and observation}

Cells were seeded on slides on a 24-well plate and were cultured for $24 \mathrm{~h}$. The slides were fixed in $4 \%$ paraformaldehyde (Servicebio, Wuhan, China) for $15 \mathrm{~min}$ at room temperature. The slides were stained with BODIPY 493/503 (\#D3922, Invitrogen, Carlsbad, CA, USA) for $45 \mathrm{~min}$ at $37^{\circ} \mathrm{C}$ and were then stained with DAPI (\#G1012 , Servicebio) for $10 \mathrm{~min}$ at $37^{\circ} \mathrm{C}$. After washing three times with PBS for 10 min each, the slides were sealed with an anti-fluorescent quenching solution (\#P36961, ProLong $^{\mathrm{TM}}$ Diamond Antifade Mountant, Invitrogen ${ }^{\mathrm{TM}}$, Carlsbad, CA, USA) for use in a confocal laser scanning microscope (Zeiss LSM 800, Carl Zeiss, German) observation.

\section{Co-localization of PSMD1/PSMD2 and LDs}

The fluorescence labelling PSMD1, PSMD2, and PLIN2 expression vectors (PSMD1-mCherry, PSMD2-mCherry and PLIN2-EGFP) were co-transfected into HepG2 cells. After $48 \mathrm{~h}$, the cells were treated with $200 \mu \mathrm{M}$ OA for another $6 \mathrm{~h}$. Then, the cells were fixed and then sealed with an anti-fluorescent quenching solution for confocal laser scanning microscope observation. The fluorescence plot analysis was performed by ImageJ software according to the instructions (https://imagej.en.softonic.com/). For the co-localization of PSMD1/PSMD2 and newly formed LDs, Livedrop was introduced to this experiment. The Livedrop [52] has been reported to be a useful fluorescence marker to label the newly formed LDs from the ER. The newly formed LDs were detected by Livedrop-EGFP within $30 \mathrm{~min}$. Then, the same experiment was performed. In our study, we detected that the newly formed LDs were 45 min old.

\section{Survival analysis and normal/cancer gene expression comparison analysis}

Survival predication was performed using the GEPIA database (http://gepia.cancer-pku.cn/). The prognosis analysis and gene expression analysis were performed according to the instructions of the creator of this database [53].

\section{Statistical analysis}

All experiments were repeated at least three times. All results are presented as the mean \pm SD. Statistical significance was assessed using Student's t-test. A p value $<0.05$ was deemed to indicate statistical significance.

\section{Results}

Both PSMD1 and PSMD2 knockdown suppresses HepG2 cell proliferation but promotes apoptosis

The idea that PSMD1 and PSMD2 play important roles in the proliferation process of tumor cells, such as breast cancer cells and lung cancer cells, is not novel. However, few studies have reported their roles in regulating the proliferation and apoptosis process in HepG2 cells. Thus, we first investigated the functions of PSMD1 and PSMD2 in HepG2 cells. The specific RNAi fragments were prepared to block the expression of PSMD1 and PSMD2individually and together. The cell proliferation capacity was detected by the MTT method, indicating that the cell proliferation process was significantly inhibited by the downregulation of PSMD1 and PSMD2 ( $<<0.05$, Fig. 1a). We then performed a cell cycle analysis to illustrate the cells in different phases. The results indicated that more cells were blocked in the S-stage by PSMD1 and PSMD2 knockdown (Fig. 1b, c). Then, the apoptosis analysis was performed through the flow cytometry method. As expected, more cells underwent apoptosis with low expression levels of PSMD1 and PSMD2 (Fig. 1d, e). To investigate the potential regulatory mechanism, we detected the expression levels of proliferation-related (Fig. 1f) and apoptosis-related genes (Fig. 1g). The expression levels of CCND1, CCND2, CCNB1, CCNE1, 

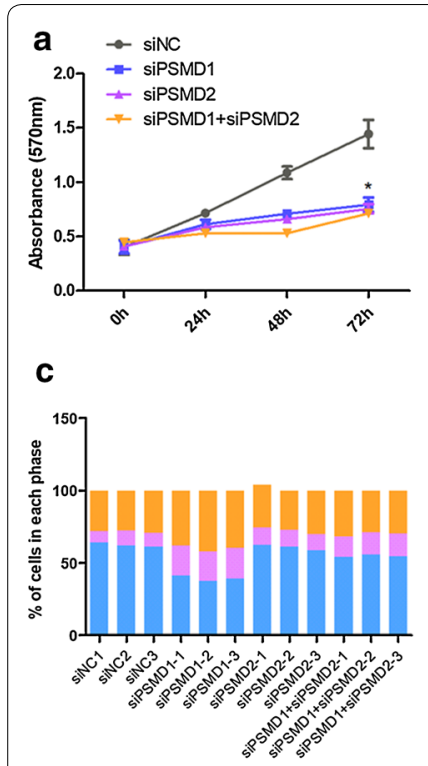

e

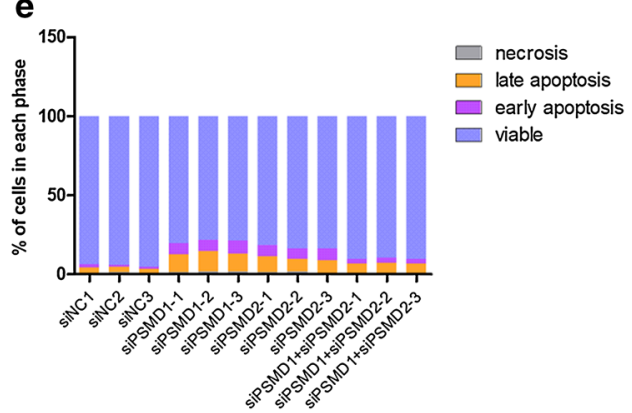

h
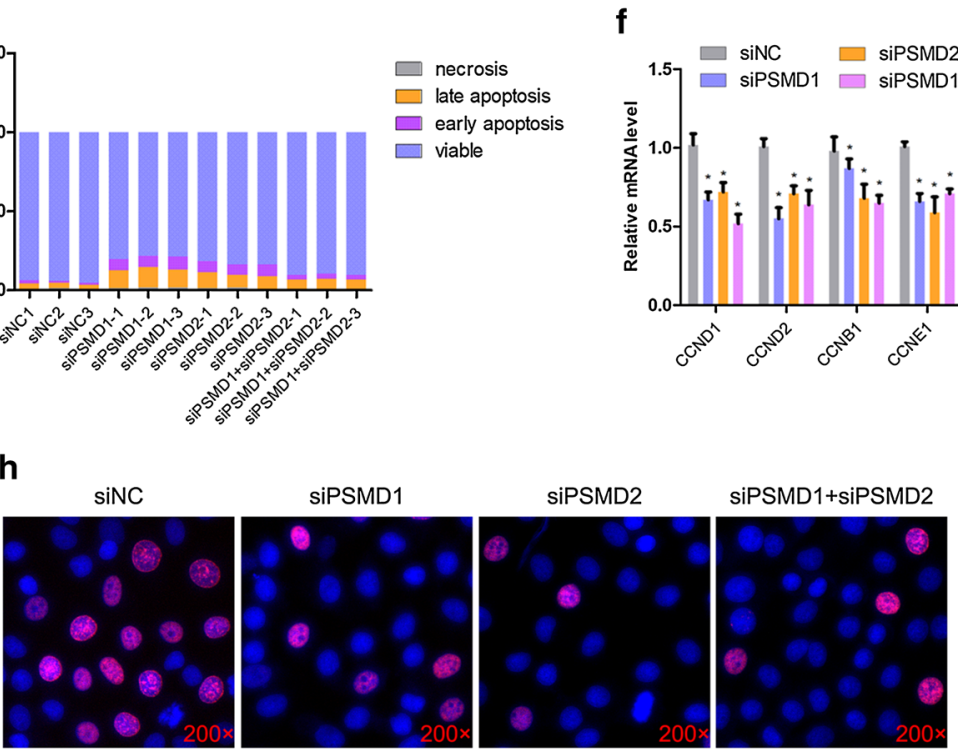

DAPI/EdU
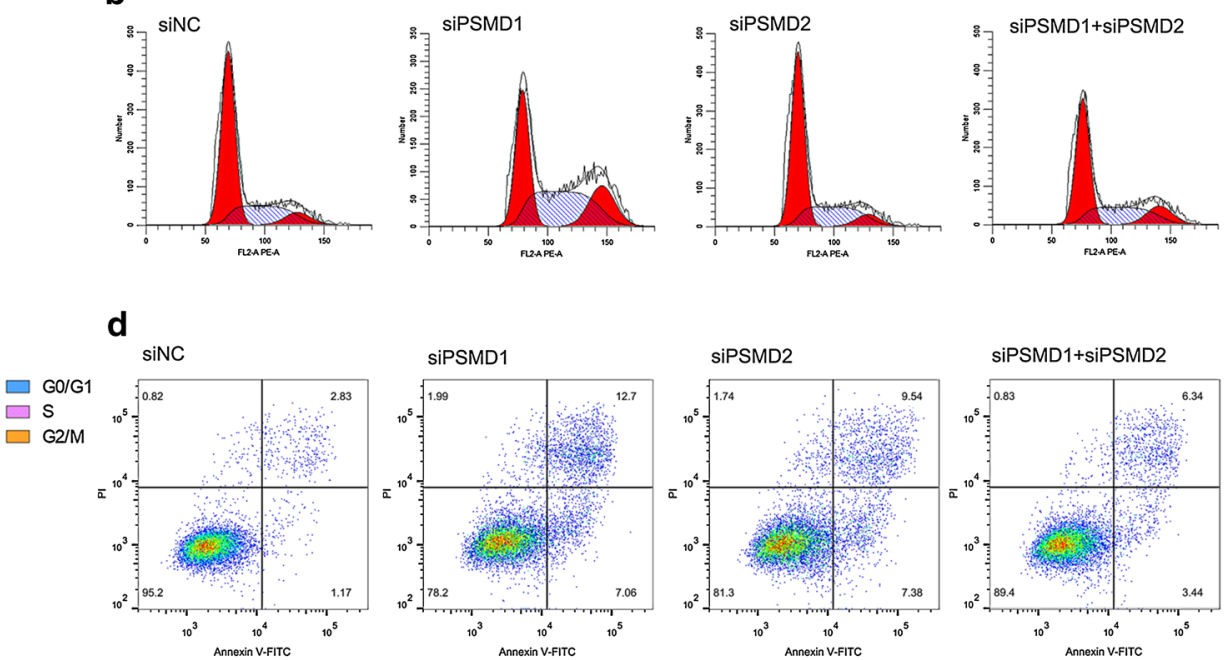

Fig. 1 PSMD1 and PSMD2 knockdown inhibits proliferation and induces cell apoptosis. a Cell proliferation was monitored with an MTT assay at the indicated time after treatment with PSMD1 and PSMD2 siRNAs in HepG2 cells. Data are presented as the mean $\pm S D(n=3),{ }^{*} p<0.05 . \mathbf{b}, \mathbf{c}$ Flow cytometric analysis of the cell cycle distribution at $48 \mathrm{~h}$ post-transfection of the negative control (NC) or PSMD1/PSMD2 siRNA in HepG2 cells. The percentages of each phase of the cell cycle (G0/G1, S, and G2/M) are shown. Data are presented as the mean $\pm \operatorname{SD}(n=3)$, ${ }^{*} p<0.05,{ }^{* *} p<0.01$. d, e HepG2 cells were collected for the detection of apoptotic cells by flow cytometry, $48 \mathrm{~h}$ after transfection. In all panels, data are presented as the mean \pm SEM of three independent assays. The statistical significance of differences between means was assessed using an unpaired Student's t-test $\left({ }^{*} \mathrm{p}<0.05 ;{ }^{* *} \mathrm{p}<0.01\right)$ vs. the NC. f Relative mRNA expression of the cell cycle-related genes after transfection of siPSMD1/siPSMD2 and siNC. Independent sample t-tests were used to analyze the statistical differences between groups. ${ }^{*} p<0.05 ;{ }^{* *} p<0.01$. g The mRNA expression levels of several apoptosis-related genes with siPSMD1/siPSMD2 and siNC in HepG2 cells. Independent sample t-tests were used to analyze the statistical differences between groups. ${ }^{*} p<0.05 ;{ }^{* *} p<0.01$. h, $\mathbf{i}$ EdU staining after PSMD knockdown. The magnification is $\times 200$. Results are shown as the mean \pm SEM of three independent experiments. Independent sample t-tests were used to analysis the statistical differences between groups. ${ }^{*} p<0.05 ;{ }^{* *} p<0.01$

and ki67 were downregulated significantly $(\mathrm{p}<0.05)$ in the siPSMD1, siPSMD2, and siPSMD1+ siPSMD2 group cells, while $C A S P 3, C A S P 8, C A S P 9$, and $F A S$ were upregulated significantly $(\mathrm{p}<0.05)$. To validate this result, the EdU assay was performed to detected cell proliferation. The number of proliferating cells was approximately 

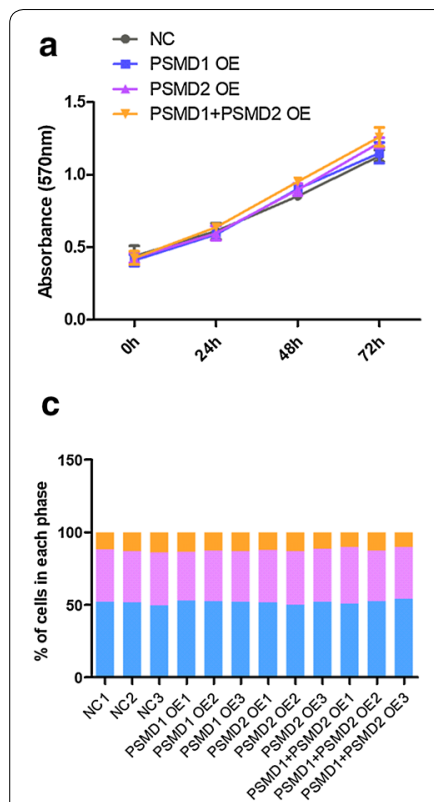

e

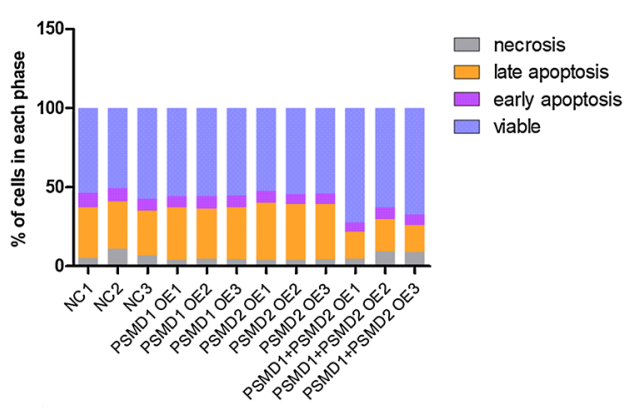

h

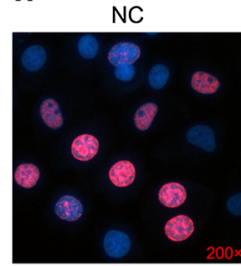

PSMD1 OE
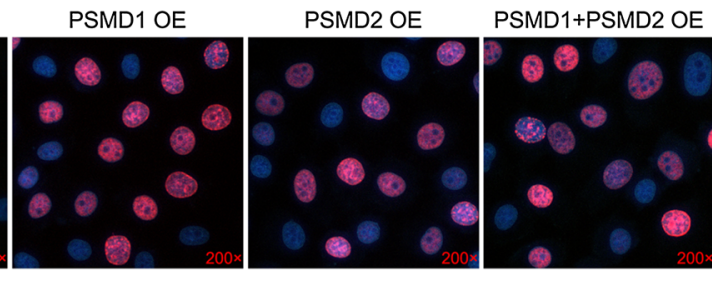
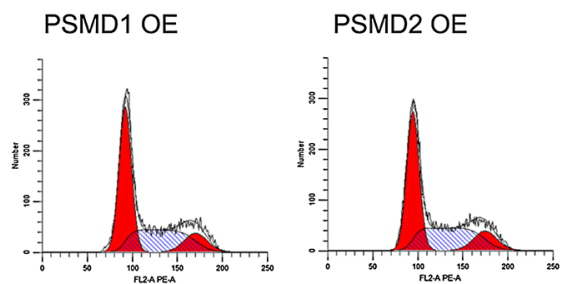

PSMD1+PSMD2 OE

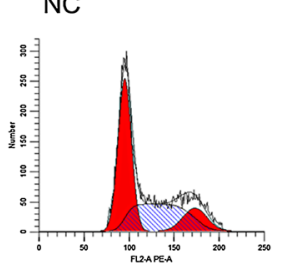

PSMD1 OE

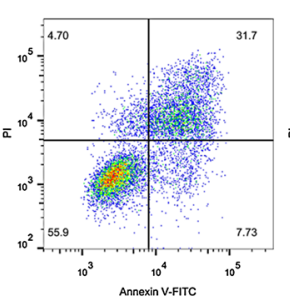

PSMD2 OE

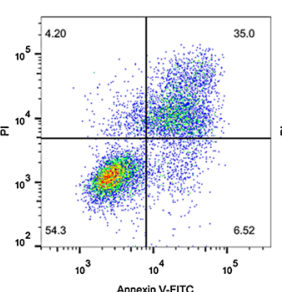

PSMD1+PSMD2 OE

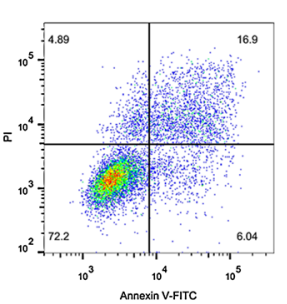

f $\square$ NC $\square$ PSMD2OE

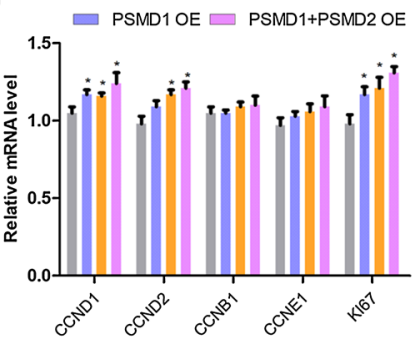

g

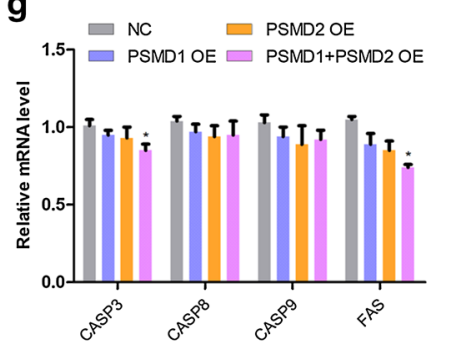

DAPI/EdU

Fig. 2 PSMD1 and PSMD2 overexpression promotes proliferation and inhibits cell apoptosis. a Cell proliferation was monitored with the MTT assay at the indicated time after treatment with PSMD1/PSMD2 overexpression in HepG2 cells. Data are presented as the mean \pm SD ( $n=3$ ), ${ }^{*} \mathrm{p}<0.05$. b, c Flow cytometric analysis of the cell cycle distribution at $48 \mathrm{~h}$ post-transfection of overexpression plasmid in HepG 2 cells. The percentages of each phase of the cell cycle (G0/G1, S, and G2/M) are shown. d, e HepG2 cells were collected for the detection of apoptotic cells by flow cytometry, $48 \mathrm{~h}$ after transfection. In all panels, data are presented as the mean \pm SEM of three independent assays. $\mathbf{f}$ Relative mRNA expression of the cell cycle-related genes after transfection of the PSMD1/PSMD2 plasmid. The statistical significance of differences between means was assessed using unpaired Student's t-tests $\left({ }^{*} p<0.05 ;{ }^{* *} p<0.01\right)$ vs. the NC. $\mathbf{g}$ The mRNA expression levels of several apoptosis-related genes with the overexpression plasmid in HepG2 cells. The statistical significance of differences between means was assessed using unpaired Student's t-tests $\left({ }^{*} p<0.05 ;{ }^{* *} p<0.01\right.$ ) vs. the NC. $\mathbf{h}$, i EdU staining after PSMD1/PSMD2 overexpression. The magnification is $200 \times$. Results are shown as the mean \pm SEM of three independent experiments. Independent sample t-tests were used to analyze the statistical differences between groups. ${ }^{*} p<0.05 ;{ }^{* *} p<0.01$

$60 \%$ of the total cells in the control group, whereas the percentages were about $40 \%, 39 \%$, and $38 \%$ in the siPSMD1, siPSMD2, and siPSMD1+ siPSMD2 groups, respectively (Fig. $1 \mathrm{~h}$, i). Taken together, PSMD1 and PSMD2 played important roles in the cell proliferation and apoptosis processes. 


\section{PSMD2 and PSMD2 overexpression promotes HepG2 cell proliferation but suppresses apoptosis}

To further investigate the functions of PSMD1 and PSMD2 in cell proliferation, PSMD1 and PSMD2 were overexpressed individually or together. The MTT assay indicated that PSMD1 and PSMD2 overexpression increased the cell proliferation capacity slightly but not significantly (Fig. 2a). We then performed the cell cycle analysis. There were no significant changes among different groups of cells (Fig. 2b, c). Subsequently, the apoptosis analysis was performed, and interestingly, the number of cells undergoing apoptosis increased only in groups with both PSMD1 and PSMD2 overexpression (Fig. 2d, e). Therefore, we detected the expression levels of genes related to proliferation (Fig. 2f) and apoptosis (Fig. 2g). Interestingly, the expression levels of CCND1, CCND2, and ki67 increased slightly but significantly $(\mathrm{p}<0.05$, Fig. 2f), while the expression levels of CASP3 and FAS decreased in the PSMD1 OE + PSMD2 OE group (Fig. 2g). To validate the result, the EdU assay was performed to detect the number of proliferating cells. There were no significant differences observed among the different treatment groups (Fig. 2h, i).

\section{PSMD1 and PSMD2 knockdown inhibits the formation of cellular lipid droplets}

Cellular lipid metabolism is important for cell proliferation and apoptosis. We investigated the effects of PSMD1 and PSMD2 on the formation of lipid droplets (LDs). Usually, cells form the fatty acid and lipid droplets de novo. The cellular LDs were marked by BODIPY493/503, a specific neutral lipid targeting dye, and the numbers and sizes of LDs in different cell groups were analyzed based on the images captured by the confocal laser scanning microscope (Fig. 3a). The LD number in the siPSMD1, siPSMD2, and siPSMD1 + siPSMD2 cell groups was significantly less than the number of control group cells $(\mathrm{p}<0.05$, Fig. $3 \mathrm{~b})$. Furthermore, we detected the capacity of neutral lipid synthesis of different group cells by treating them with $200 \mu \mathrm{M}$ oleic acid (OA) for $12 \mathrm{~h}$. Before OA treatment experiment, we detected the toxicity of OA on both HepG2 cells and Huh7 cells by utilizing CCK8 method. The results showed that OA treatment showed less toxicity on these two cell lines with the treatment time of 6 h, $12 \mathrm{~h}$ and $24 \mathrm{~h}$ (Additional file 1: Fig. S1C, D). Subsequently, we found that siPSMD1, siPSMD2, and both interfered cell groups contained fewer LDs than the control cells ( $\mathrm{p}<0.05$, Fig. $3 \mathrm{c})$. Then, we calculated the LD size and found that PSMD1 and PSMD2 interference did not change the LD size in the absence of OA, whereas the suppression of PSMD1 and PSMD2 increased the diameters of LDs in FA-rich medium (Fig. 3d, e). To further validate the regulatory roles of PSMD1 and PSMD2 in lipid metabolism, we performed the same experiments using another human hepatocellular carcinoma cell line, Huh7. We found that the knockdown of PSMD1 and/or PSMD2 decreased the cellular LD number significantly $(\mathrm{p}<0.05$, Additional file 3: Fig. S2A-C).

\section{PSMD1 and PSMD2 overexpression promotes the formation} of lipid droplets

To further investigate the effects of PSMD1 and PSMD2 on cellular LD formation and growth, we overexpressed these two genes in HepG2 cells and detected the LD number and size by fluorescence labeling of LDs. In both the absence and presence of OA, PSMD1 and PSMD2 overexpression significantly increased the number of cellular LDs compared with that of control cells $(\mathrm{p}<0.05$, Fig. 4a-c). Interestingly, larger LDs were observed in cells with PSMD1 and/or PSMD2 overexpression compared with control cells (Fig. 4a, d), whereas the difference in LD size between the overexpression and control group cells was decreased and almost disappeared in the presence of OA (Fig. 4e), although the overexpression group cells contained sporadic larger LDs with diameters between 1 and $2 \mu \mathrm{m}$ (Fig. 4a, e). For further validation, the Huh7 cells were utilized to detect whether overexpression of PSMD1 and/or PSMD2 affected the cellular LD number. We found that the overexpression of PSMD1 and/or PSMD2 increased the LD diameter in Huh7 cells (Additional file 3: Fig. S2D-F). The phenotypes seen in the overexpression experiment contrasted with the results seen in the interference experiment, and therefore, PSMD1 and PSMD2 were potential positive regulators in the cellular lipid formation process.

\footnotetext{
(See figure on next page.)

Fig. 3 PSMD1 and PSMD2 knockdown regulates the number and size of cellular lipid droplets. a Detection of the cellular LDs marked by BODIPY493/503 through a laser scanning confocal microscope. The HepG2 cells were seeded on the slide in a 24-well plate. Then, the cells were transfected with PSMD1/PSMD2 or NC siRNAs for $48 \mathrm{~h}$. Subsequently, the cells were treated with $200 \mu \mathrm{M}$ oleic acid for another $6 \mathrm{~h}$. Then, the cells were fixed and stained by BODIPY493/503 and DAPI for observation by microscope. b, $\mathbf{c}$ The number of cellular LDs of different groups of cells in the absence or present of OA. ImageJ software was used for the analysis. The statistical significance of differences between means was assessed using an unpaired Student's t-test $\left(n=20 ;{ }^{*} p<0.05 ;{ }^{* *} p<0.01\right)$ vs. NC. $\mathbf{d}$, e The count of the size of cellular LDs of different groups of cells in the absence or present of OA. ImageJ software was used for the analysis. Statistical significance of differences between means was assessed using an unpaired Student's t-test $\left(n=10 ;{ }^{*} p<0.05 ;{ }^{* *} p<0.01\right)$ vs. NC
} 

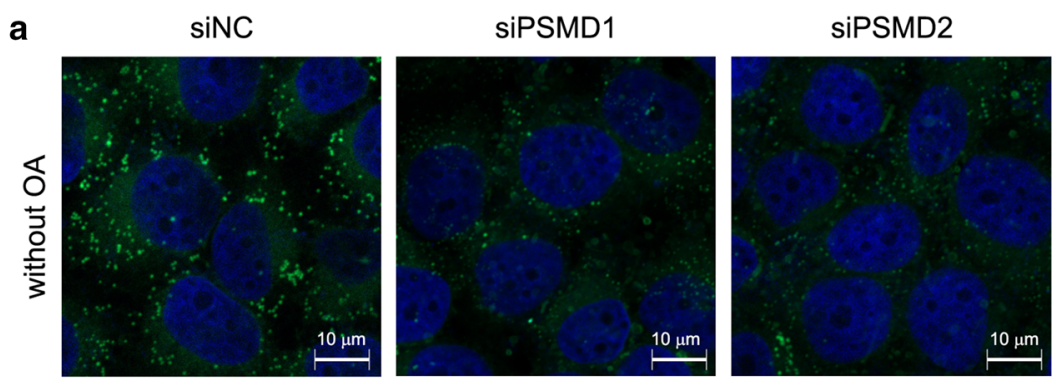

siPSMD1+siPSMD2
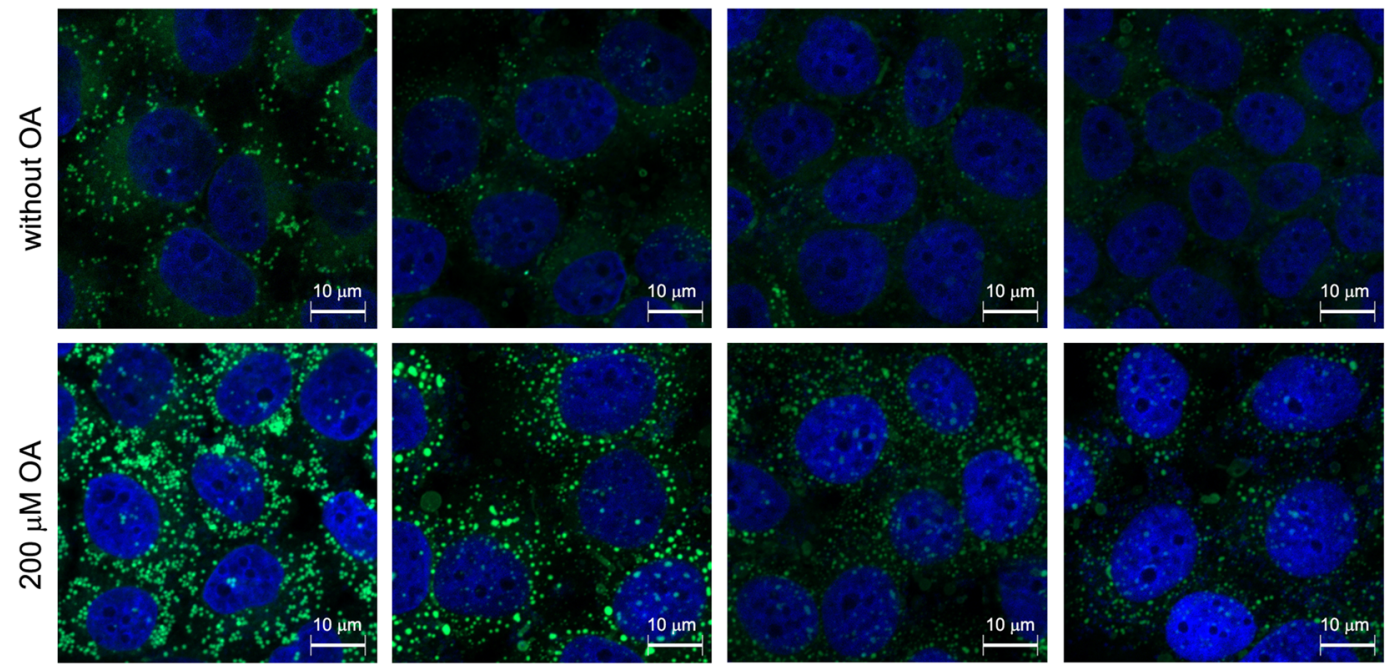

DAPI/BODIPY 493/503

b

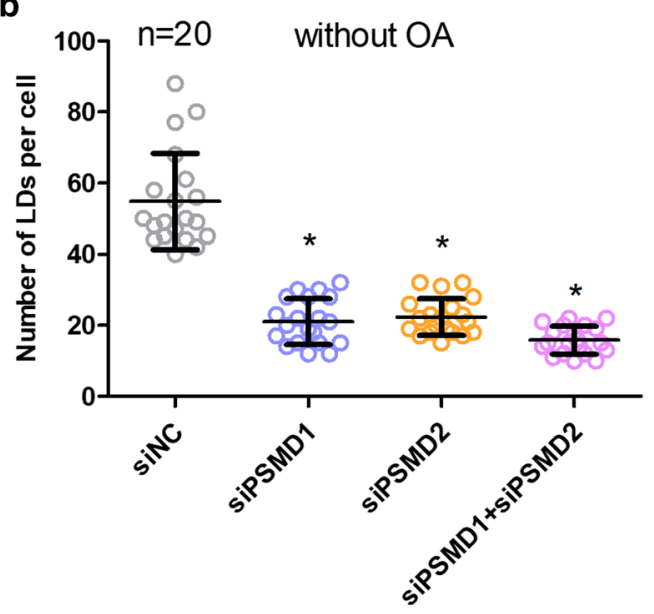

d

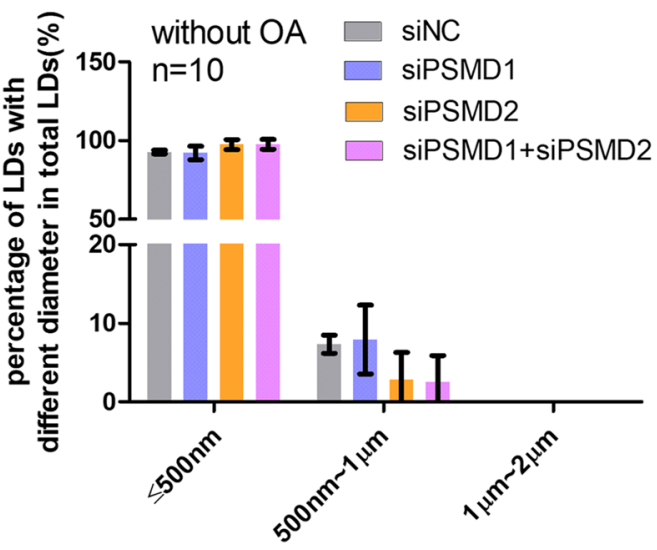

c

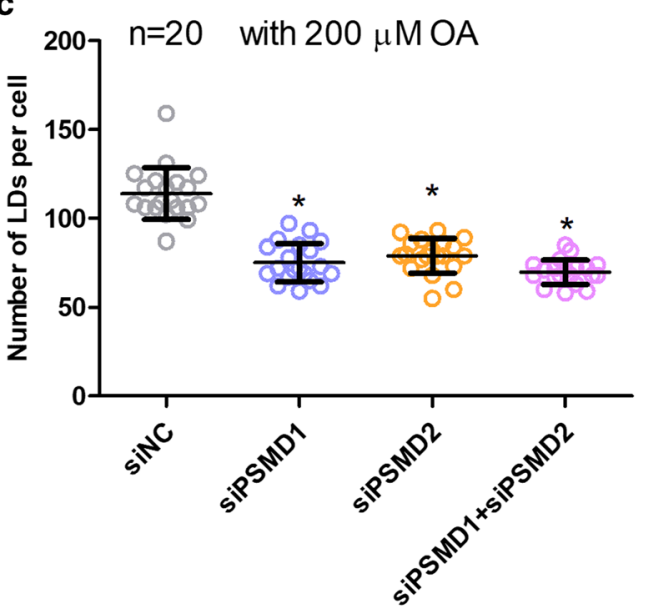

e

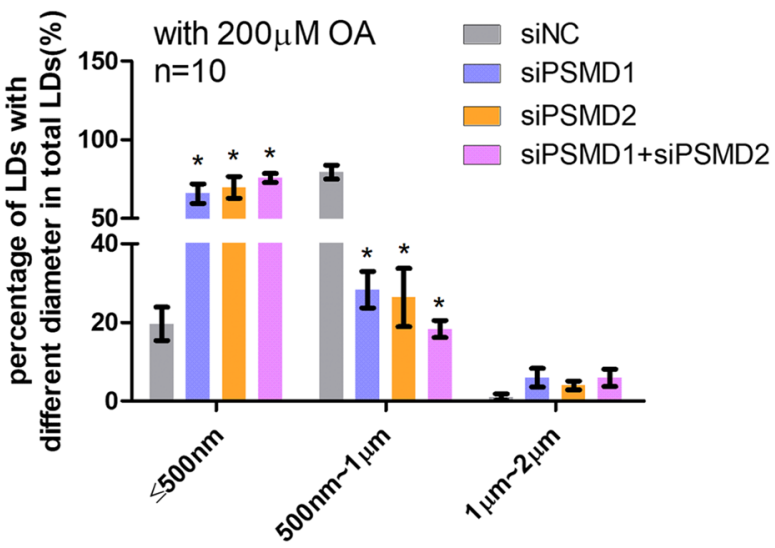




\section{PSMD1 and PSMD2 regulate the expression level of FA and lipid synthesis-related genes}

The changes in LD number and size prompted us to investigate the effects of PSMD1 and PSMD2 on the expression levels of lipid metabolic-related genes including the FA-related genes (SREBF1, FASN, SCD1, and ACSL3) and neutral lipid synthesis-related genes (PLINs, LIPINs, FITMs, DGATs, PPAR , SEIPIN, and FSP27). We first investigated the effect of the suppression of PSMD1 and PSMD2 expression on these genes. The efficiency of interference was reflected by the mRNA levels of PSMD1 and PSMD2 detected by qPCR (Fig. 5a), and the expression levels of PSMD1 and PSMD2 decreased by approximately $70 \%$. Then, the expression levels of FA and lipid synthesis-related genes were detected. As expected, the expression levels of SREBF1, FASN, SCD1, and ACSL3 were significantly decreased in the interference group cells compared with the control cells $(\mathrm{p}<0.05$, Fig. 5b), which suggests that the de novo FA synthesis capacity was decreased in the interference group cells. Moreover, the expression of neutral lipid synthesisrelated genes, such as DGAT1, DGAT2 and PPARy, was decreased by the suppression of PSMD1 and/or PSMD2 ( $\mathrm{p}<0.05$, Fig. 5c). Interestingly, we found that PSMD1 and PSMD2 showed different effects on the expression of PLIN2, a well-known LD marker gene. PSMD1 interference promoted the expression of PLIN2, whereas the PSMD2 interference decreased PLIN2 expression. Additionally, PSMD1 interference increased the expression of SEIPIN, also known as BSCL2, which plays an important role in cellular LD formation and budding off, whereas PSMD2 interference did not change the expression of SEIPIN. Subsequently, we also investigated the effects of PSMD1 and/or PSMD2 overexpression on the expression of these genes. PSMD1 and PSMD2 were highly overexpressed (Fig. 5d). The expression of SREBF1, FASN, $S C D 1$, and $A C S L 3$ was significantly increased in the PSMD1 OE + PSMD2 OE cell groups $(\mathrm{p}<0.05$, Fig. $5 \mathrm{e})$. Furthermore, the expression levels of DGAT1, DGAT2, and $P P A R \gamma$ were significantly upregulated by PSMD1 and $P S M D 2$ overexpression ( $\mathrm{p}<0.05$, Fig. $5 \mathrm{f}$ ). It was interesting that the expression level of SEIPIN was downregulated by PSMD1+PSMD2 OE $(\mathrm{p}<0.05)$, which was in contrast to the results of the interference experiment. This result suggests that PSMD1 and PSMD2 may regulate SEIPIN expression.

To investigate the molecular mechanism by which PSMD1 and PSMD2 regulate FA and lipid synthesisrelated genes, we detected two classical pathways, the ASK1-p38-JNK and AKT signaling pathways. We detected the phosphorylated ASK1, p38, and JNK1/2 levels and found that the p-ASK1, p-p38, and p-JNK $1 / 2$ levels were decreased in interference group cells compared with control cells (Fig. 5g, h). Additionally, the p-AKT level was also decreased in the interference group cells compared with the control cells (Fig. $5 \mathrm{~g}, \mathrm{~h}$ ). Subsequently, we investigated the effects of PSMD1 and PSMD2 overexpression on these two signaling pathways. As expected, the p-AKT and p-ASK1 levels increased significantly but mildly ( $\mathrm{p}<0.05$, Fig. $5 \mathrm{i}, \mathrm{j})$. Additionally, the p-p38 level was not significantly different (Fig. 5i, j). Although the effects of PSMD1 and PSDM2 overexpression on ASK1 and AKT signaling were not obvious, we also considered that PSMD1 and PSMD2 regulated these two signaling pathways, thereby regulating FA and neutral lipid synthesis.

\section{PSMD1 and PSMD2 regulate cellular lipid metabolism}

To validate that PSMD1 and PSMD2 regulate cell proliferation through modulating cellular FA and lipid content, we performed a rescue experiment that overexpressed SREBF1 or PPARY in the PSMD1 and PSMD2 knockdown cells. We showed that PSMD1 and PSMD2 knockdown inhibited cell proliferation. Subsequently, we tried to increase the FA level by overexpressing SREBF1 in PSMD1 and PSMD2 knockdown cells, because SREBF1 could promote the transcription of FA-synthesis-related enzymes. Then, the capacity of cell proliferation was detected by EdU assay. The results showed that SREBF1 overexpression increased the number of proliferating cells in the siPSMD1, siPSMD2, and siPSMD1+ siPSMD2 groups compared with the corresponding control groups ( $p<0.05$, Fig. 6a, b). Moreover, the expression levels of proliferation-related genes were also detected by qPCR. Although SREBF1 overexpression did not recover the

\footnotetext{
(See figure on next page.)

Fig. 4 PSMD1 and PSMD2 overexpression regulates the number and size of cellular lipid droplets. a Detection of the cellular LDs marked by BODIPY493/503 through a laser scanning confocal microscope. The HepG2 cells were seeded on the slide in a 24-well plate. Then, the cells were transfected with PSMD1/PSMD2 or NC overexpression plasmid for $48 \mathrm{~h}$. Subsequently, the cells were treated with $200 \mu \mathrm{M}$ oleic acid for another $6 \mathrm{~h}$. Then, the cells were fixed and stained by BODIPY493/503 and DAPI for observation by microscope. b, c The number of cellular LDs from different groups of cells in the absence or present of OA. ImageJ software was used for the analysis. The statistical significance of differences between means was assessed using an unpaired Student's t-test $\left(n=20 ;{ }^{*} p<0.05 ;{ }^{*} p<0.01\right)$ vs. NC. $\mathbf{d}$, e The size of cellular LDs of different groups of cells in the absence or present of OA. ImageJ software was used for the analysis. The statistical significance of differences between means was assessed using an unpaired Student's t-test $\left(n=10 ;{ }^{*} p<0.05 ;{ }^{* *} p<0.01\right)$ vs. NC
} 

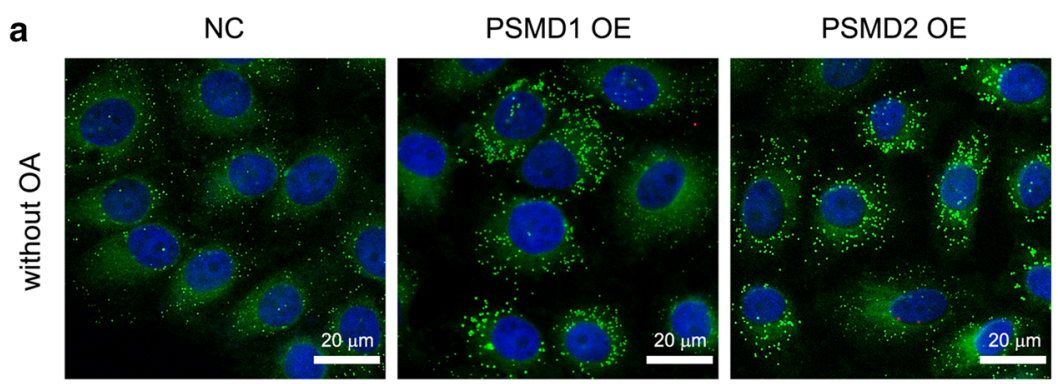

PSMD1+PSMD2 OE
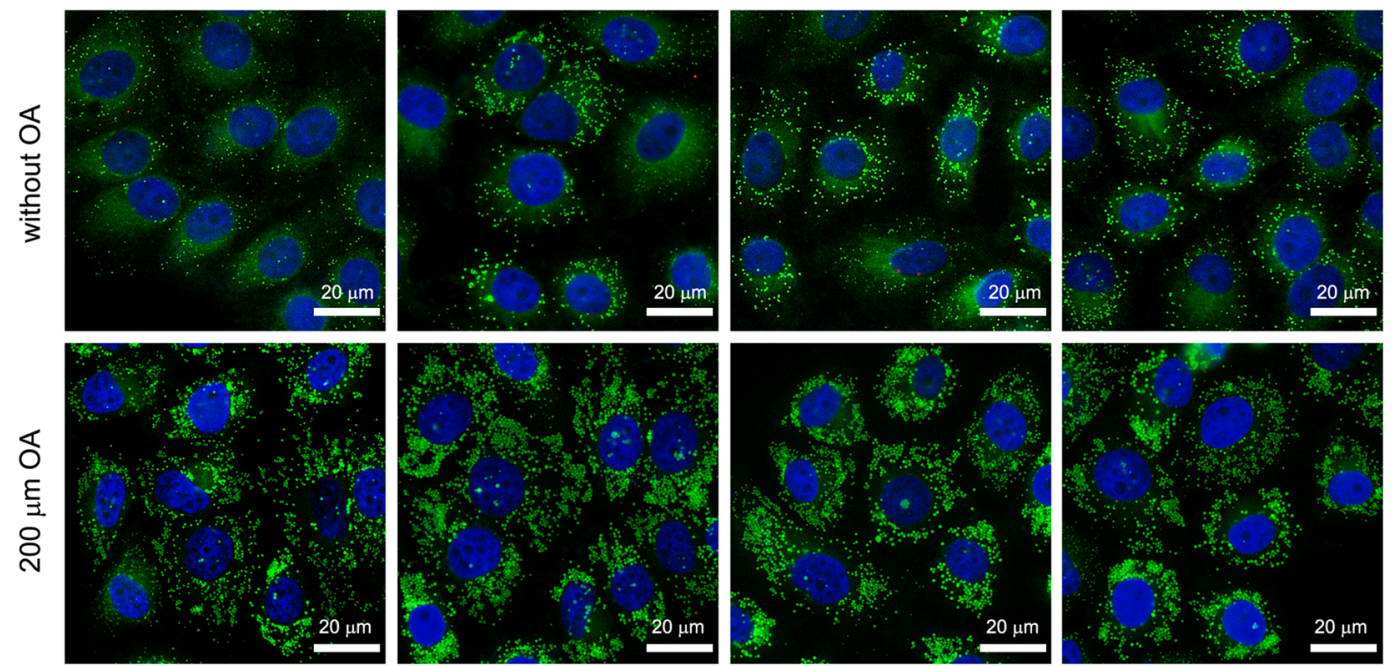

DAPI/BODIPY 493/503
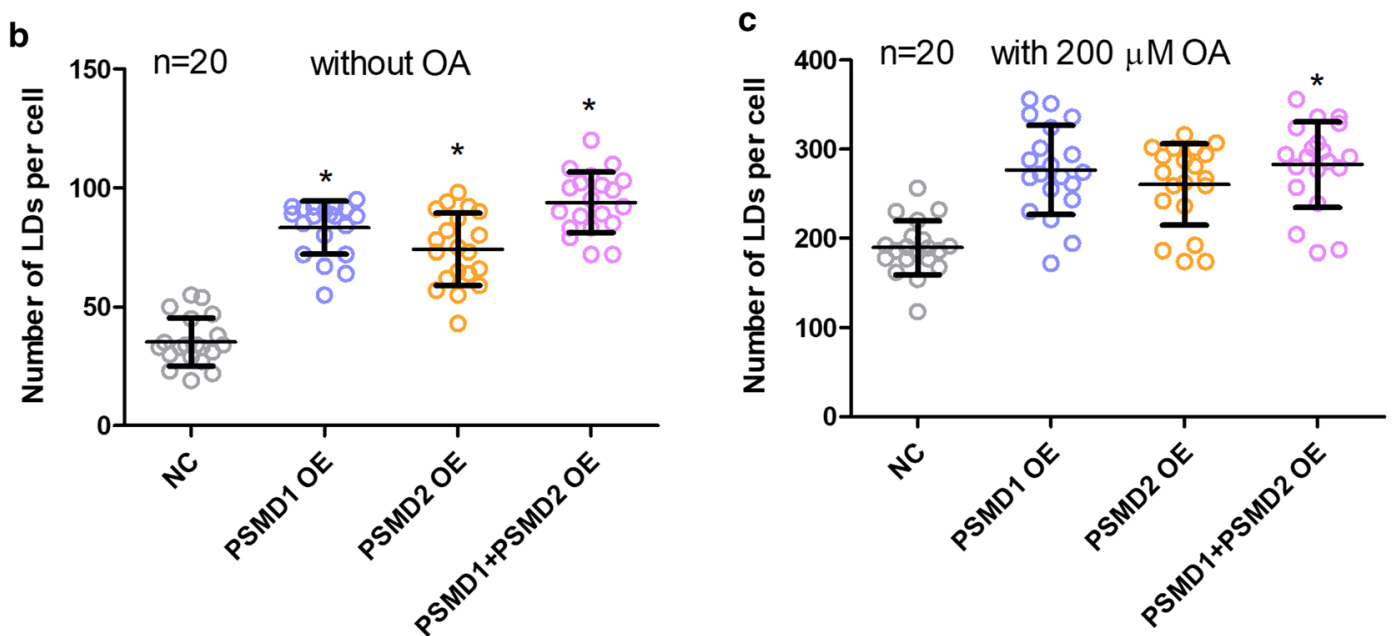

d

e
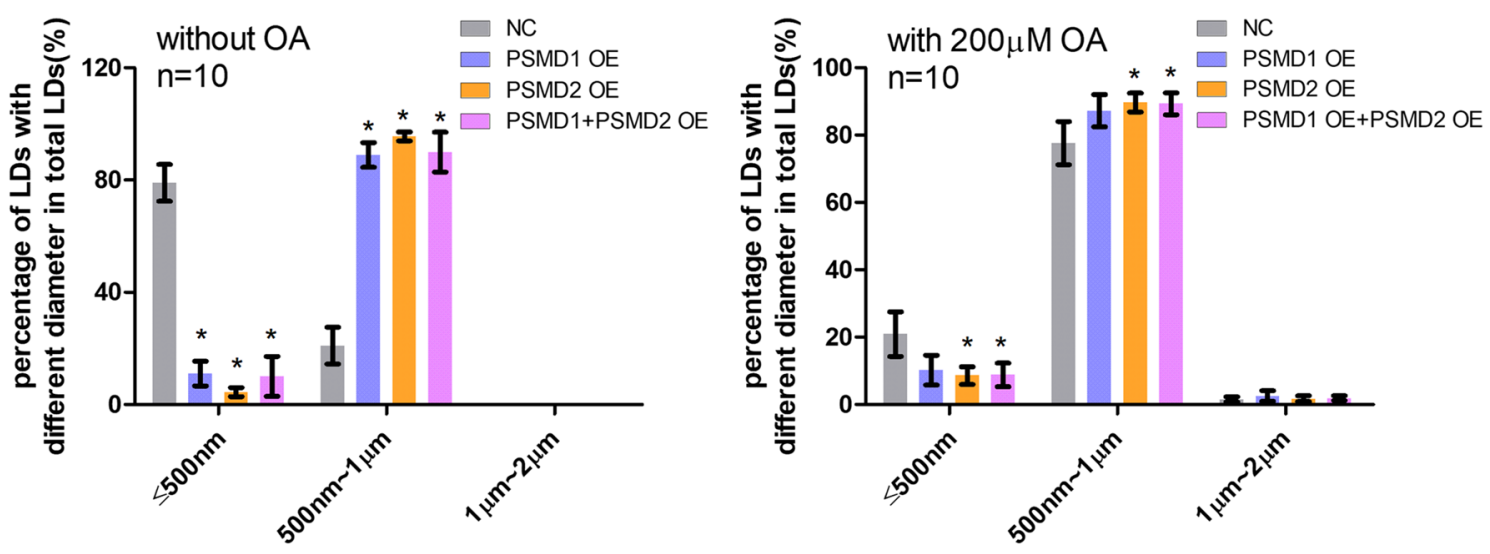

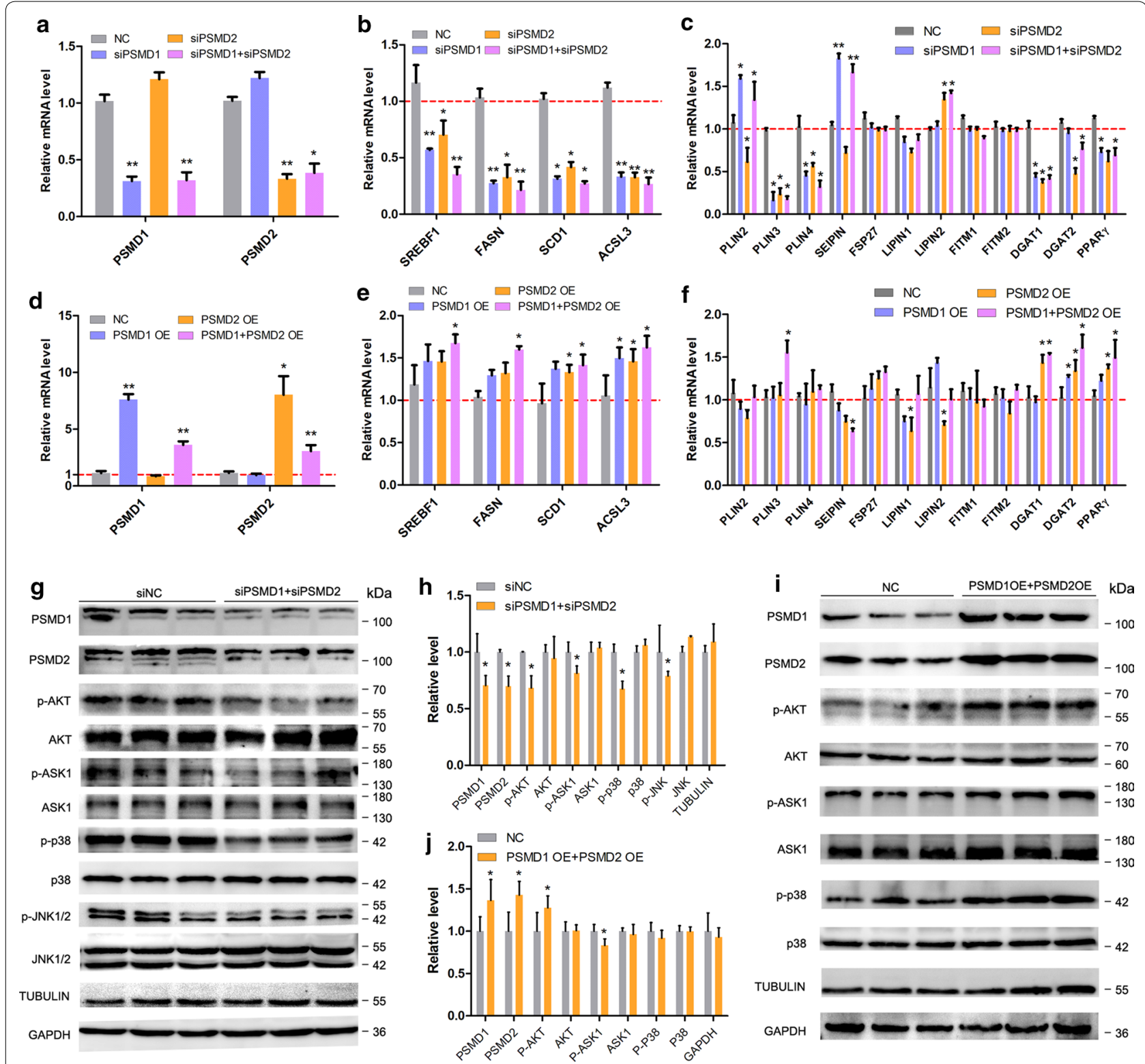

Fig. 5 PSMD1 and PSMD2 regulate the expression level of fatty acids (FAs) and lipid synthesis-related genes. a Interference efficiency detection by qRT-PCR. $\mathbf{b}$ The expression level of fatty acid synthesis-related genes was detected by qRT-PCR. $\mathbf{c}$ The expression level of lipid synthesis-related genes was detected by qRT-PCR. $\mathbf{d}$ Overexpression efficiency detection by qRT-PCR. e The expression level of fatty acid synthesis-related genes was detected by qRT-PCR. fThe expression level of lipid synthesis-related genes was detected by qRT-PCR. $\mathbf{g}$ The ASK1-p38-JNK and AKT signaling in groups of interfered cells and control cells was detected by Western Blot experiments. TUBULIN and GAPDH were the reference proteins. $\mathbf{h}$ Grey value analysis of $\mathbf{g}$. ImageJ software was used for this analysis, according to the instructions. i The ASK1-p38-JNK and AKT signaling in the overexpression cell group and control cells was detected by Western Blot experiments. TUBULIN and GAPDH were the reference proteins. $\mathbf{j}$ Grey value analysis of $\mathbf{i}$. ImageJ software was used for this analysis, according to the instructions. The statistical significance of differences between means was assessed using an unpaired Student's t-test $\left(n=3 ;{ }^{*} p<0.05 ;{ }^{* *} p<0.01\right)$ vs. NC

proliferation impaired by PSMD1 and/or PSMD2 interference totally, the proliferation capacity did increase compared with that of the control (Fig. 6b, c). Furthermore, PPARY overexpression increased the proliferation capacity of PSMD1 and/or PSMD2 knockdown cells (Fig. 6d, e). Additionally, the expression levels of proliferation-related genes, including CCNs and ki67, increased compared with that of the corresponding control group ( $<<0.05$, Fig. $6 f)$. These two rescue experiments indicated that increasing the lipid content 
in cells could partly recover the PSMD1 and PSMD2 interference-induced inhibition of proliferation. The results showed that PSMD1 and PSMD2 can affect cell proliferation by regulating cellular lipid metabolism.

\section{PSMD1 and PSMD2 localize to the surface of lipid droplets}

We detected the subcellular localization of PSMD1 and PSDM2 and the co-localization of PSMD and LDs. PSMD1 and PSMD2 are the components of the $19 S$ subunit of proteasome; therefore, they are mainly distributed in the cytoplasm. We labelled PSMD1 and PSMD2 by the mCherry-tag in their C-terminals, and their distribution was captured by a confocal laser scanning microscope (Fig. 7a). As expected, PSMD1 and PSMD2 were localized in the cytoplasm (Fig. 7a). Then, we labelled PSMD1 by an EGFP-tag in its C-terminal to determine the co-localization of PSMD1 and PSMD2. The results showed that PSMD1 and PSMD2 share the same localization (Fig. 7b). Furthermore, we investigated the co-localization of PSMD1/PSMD2 and cellular LDs. The signals of PSMD1-mCherry/PSMD2mCherry and BODIPY493/503 were captured and the images of Fig. $7 \mathrm{c}, \mathrm{d}$ showed that PSMD1/PSMD2 were localized to the outside of the LDs. To validate the PSMD1/PSMD2 localization accurately, the PLIN2EGFP was co-transfected with the PSMD1-mCherry or PSMD2-mCherry expression vector, because PLIN2 is a well-known LD marker localized to the surface of LDs. By fluorescence distribution analysis, the signals of PSMD1/PSMD2 were almost overlapped with the signal of PLIN2 (Fig. 7e, f). It should be noted that PSMD1/PSMD2 are not strict peri-LD proteins, because we did not observe the "round-ring" signal like we did for PLIN2. According to these results, we conclude that PSMD1 and PSMD2 are able to localize to cellular LDs, which could be the potential method by which PSMD1 and PSMD2 regulate cellular LD formation and growth.

It is well known that LDs are generated from the endoplasmic reticulum (ER). The LDs can carry proteins from the ER and recruit proteins through the ARF-COPI system. Therefore, we further investigated the source of LD localized PSMD1/PSMD2 proteins. We detected the signals of Livedrop-EGFP and PSMD1-mCherry/PSMD2mCherry at $45 \mathrm{~min}$ after $\mathrm{OA}$ treatment. The fluorescence analysis showed that two signals shared a high level of overlap, which indicated that PSMD1 and PSMD2 had localized to the newly formed LDs (Fig. $7 \mathrm{~g}, \mathrm{~h}$ ). This result suggests that LDs might carry PSMD1 and PSMD2 from the ER during their generation.

\section{High expression of PSMD1 and PSMD2 is associated with the poor prognosis of liver hepatocellular carcinomas} To investigate the effect of high expression of PSMD1 or PSMD2 on the prognosis of liver hepatocellular carcinoma (LIHC), we analyzed the expression levels of PSMD1 and PSMD2 in LIHC via the GEPIA (gene expression profiling interactive analysis) database (http:// gepia.cancer-pku.cn/). The data showed that PSMD1 and PSMD2 are highly expressed in LIHC (Fig. 8a, b). Furthermore, the results showed that LIHC with high expression of PSMD1 and PSMD2 is associated with a poor prognosis (Fig. 8c, d).

\section{Discussion}

In the present study, we identified a novel way in which PSMD1 and PSMD2 promote tumor cell proliferationnamely, via increasing cellular FA and lipid synthesis. It is not novel that the proteasome can regulate the proliferation and apoptosis of tumor cells $[54,55]$, because proteasomes are associated with the degradation of the majority of cellular proteins. Therefore, as the important subunits of the 26S proteasome, PSMD1 and PSMD2 also regulate tumor cell growth. Many previous studies also have reported their function in cell proliferation. For example, PSMD1 could regulate breast cancer cell growth [41], and PSMD2 can regulate tumor cell proliferation in lung cancer and breast cancer $[39,56]$. Furthermore, PSMD2 reduces proliferation and induces apoptosis in lung cancer cells, and the overexpression of PSMD2 could stimulate cell growth in SMMC-7721 and NIH-3T3 cells [40, 57]. However, the way in which PSMD1 and PSMD2 regulate tumor cell proliferation is not totally clear. Previous studies demonstrated that PSMD1 or PSMD2 regulate the expression levels of p53, p21, and p27 [39-41], which are cell cycle and cell growth regulators. Our findings provide new insight into the regulatory roles of PSMD1 and $P S M D 2$ in tumor cell proliferation via regulating lipid metabolism.

\footnotetext{
(See figure on next page.)

Fig. 6 PSMD1 and PSMD2 regulate cellular lipid metabolism. HepG2 cells were seeded in the 6-well plate. Then, the cells were transfected with PSMD1/PSMD2 siRNAs or SREBF1/PPARY overexpression vectors or control siRNA or a control overexpression vector. a, $\mathbf{d}$ Cell proliferation capacity was monitored by the EdU assay. b, e Statistical analysis was performed on the EdU assay. The magnification is 200x. Results are shown as the mean \pm SEM of three independent experiments. Independent sample t-tests were used to analyze the statistical differences between groups. ${ }^{*} p<0.05 ;{ }^{* *} p<0.01$. c, f Relative mRNA expression of the cell-cycle-related genes. Independent sample t-tests were used to analysis the statistical differences between groups $(n=3),{ }^{*} p<0.05 ;{ }^{* *} p<0.01$
} 


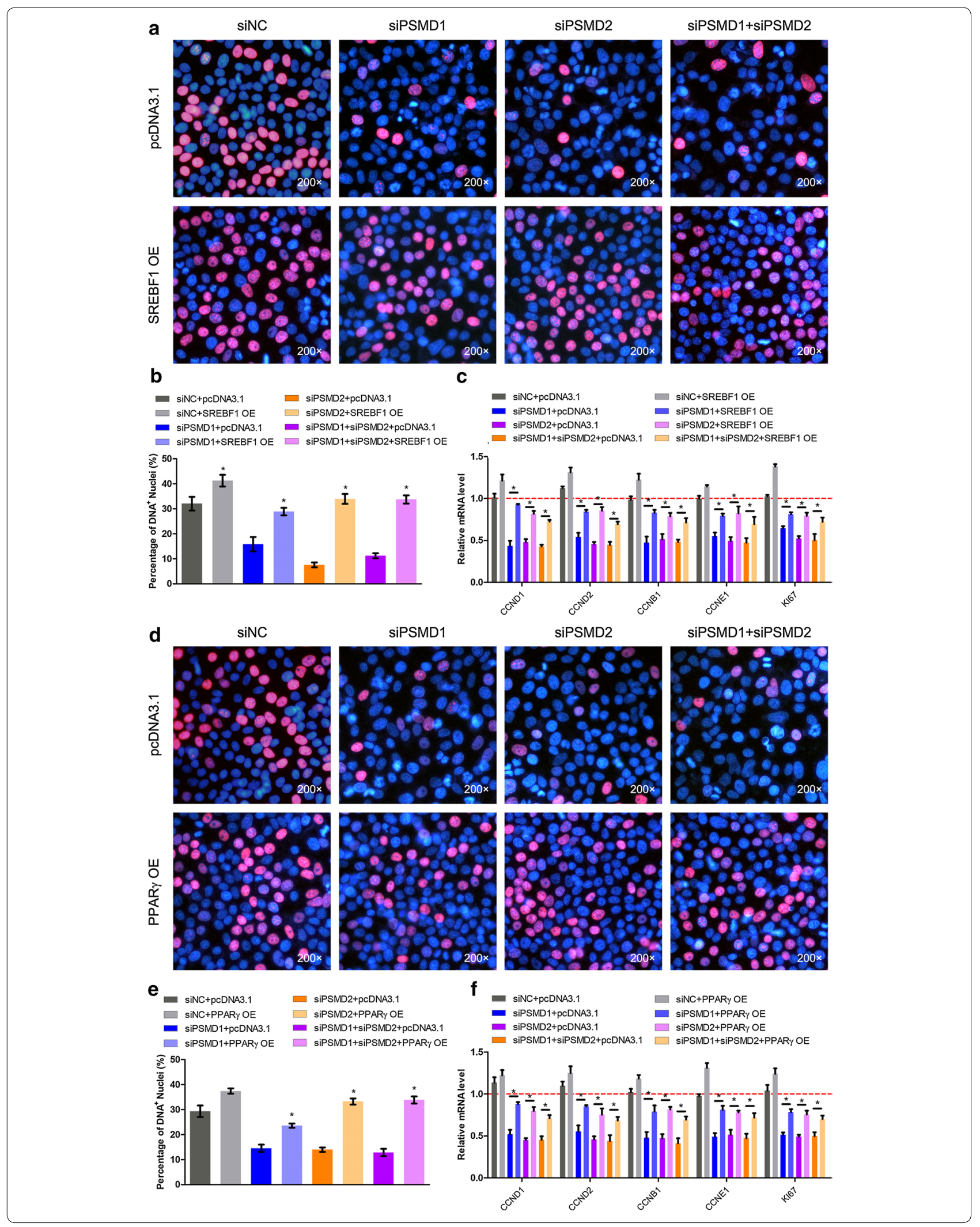


Recently, lipid metabolism was found to be important for the proliferation and growth of tumor cells. Cells need many kinds of lipids to support their duplication and growth, and they also require enough FAs for necessary biological processes. Cellular FAs and lipids are usually stored in LDs, novel organelles that have been known about for in decades, which play important roles in many biological processes such as lipid formation and degradation, cell proliferation and apoptosis, anti-stimulation, and cellular immunity [19, 58-63]. Recently, researchers found the LDs play an important role in tumor carcinogenesis and metastasis. Aboumrad et al. identified that a high number of lipid vesicles in the cytoplasm is a characteristic of mammary carcinoma [64]. Additionally, Ramos et al. reported that high lipid-containing mammary carcinoma has more aggressive behavior [6]. Lipid-rich characterization has become a clinically distinctive form of carcinoma $[6,65]$. A high level of LDs is associated with higher tumor aggressiveness [15] and chemotherapy resistance [14], and additionally, tumorigenesis-related proteins can be recruited and stored in LDs [66-68], such as PI3K, ERK1, and ERK2. Tumor cells can regulate the LD content via the EGFR-PI3K-mTOR and FOXO/ SIRT6 pathways, and LDs also regulate the proliferation and growth of tumor cells via membrane lipid and energy formation [69-74], which establishes a tight association between LDs and tumor cells.

It is very interesting that PSMD1 and PSMD2 can regulate the cellular LD content. As far as we know, no study has reported this regulatory function of PSMD1 and PSMD2 in tumor cells. It should be noted that the idea that the proteasome pathway regulates LD formation, stabilization, and degradation is not novel, and there are many studies about it. For example, the proteasome inhibitor MG132 can suppress the degradation of ADRP (also known as PLIN2) [75], and additionally, a proteasome-dependent pathway can regulate the level of ADRP to modulate the cellular TG content [76]. Moreover, Doa10, an ER-associated degradation ubiquitin ligase, is able to regulate the levels of some LD proteins
[77], and additionally, the ubiquitin ligases and Spartin/ SPG20 can regulate the number and size of LDs [78]. Furthermore, SIRT7 controls hepatic lipid formation and accumulation via regulating the ubiquitin-proteasome pathway, and SIRT7 knockout mice have shown resistance to high-fat-diet induced fatty liver [79]. Moreover, a previous functional genomic screen study in Drosophila S2 cells suggested that proteasomes are involved in the regulation of cellular lipids [80]. All of these studies demonstrated that UPS is essential for LD biology. However, ubiquitin-proteasome is a huge system, which consists of numerous components. The functions and regulatory mechanisms of these components are poorly understood. In this study, we focused on the two important subunits, PSMD1 and PSMD2, which could affect the cellular lipid content. We detected the FA and lipid synthesis enzyme expression levels during PSMD1/ PSMD2 knockdown or cell overexpression, and the results indicated that $P S M D 1$ and $P S M D 2$ indeed affect the expression levels of FASN, SCD1, SREBF1, DGAT, and $P P A R Y$ (Fig. 5). Although some changes in expression were mild, significant changes in the LD number can be observed in Figs. 3a and $4 \mathrm{a}(\mathrm{p}<0.05)$, indicating that the capacity of cellular FA and de novo lipid synthesis indeed changed. Subsequently, we also investigated the pathways impacted by PSMD1 and PSMD2. Previous studies showed that ASK1-p38-JNK signaling regulates the expression level of SREBF1 and the activation of SREBP1c, which could regulate the de novo cellular FA synthesis process [81-85]. Additionally, AKT signaling is important for cellular metabolism as it regulates cell proliferation and differentiation [86-93]. We found that PSMD1/PSMD2 knockdown impaired ASK1 and AKT signaling, which indicates that cellular lipid formation and energy metabolism were suppressed. This genotype corresponds to the phenotype where cell proliferation was inhibited and apoptosis was promoted (Fig. 1). On the other hand, PSMD1/PSMD2 overexpression enhanced ASK1 and AKT signaling, although the changes were mild (Fig. 5i, j), which corresponds

\footnotetext{
(See figure on next page.)

Fig. 7 PSMD1 and PSMD2 localize to the surface of lipid droplets. Fluorescence expression vectors were constructed, including PSMD1-mCherry, PSMD2-mCherry, PSMD1-EGFP, PLIN2-EGFP, and Livedrop-EGFP. a PSMD1-mCherry or PSMD2-mCherry was transfected into cells for $48 \mathrm{~h}$. Then, the cells were fixed and stained by DAPI. The images were captured by laser scanning confocal microscope (bar = $10 \mu \mathrm{m})$. b PSMD1-EGFP and PSMD2-mCherry were co-transfected into cells for $48 \mathrm{~h}$. Then, the cells were fixed and stained by DAPI. The images were captured by a laser scanning confocal microscope $(\mathrm{bar}=10 \mu \mathrm{m})$. The fluorescence plot was analyzed by ImageJ software. $\mathbf{c}, \mathbf{d}$ The cells were transfected with PSMD1-mCherry or PSMD2-mCherry for $48 \mathrm{~h}$, and then the cells were treated with $200 \mu \mathrm{M}$ oleic acid (OA) for another $6 \mathrm{~h}$. Then, the cells were fixed and stained by BODIPY493/503 and DAPI. The images were captured by a laser scanning confocal microscope (bar $=10 \mu \mathrm{m})$. e, $\mathbf{f}$ The cells were co-transfected with PSMD1-mCherry or PSMD2-mCherry and PLIN2-EGFP vectors for $48 \mathrm{~h}$, and then the cells were treated with $200 \mu \mathrm{M} O \mathrm{~A}$ for another $6 \mathrm{~h}$. Then, the cells were fixed and stained by BODIPY493/503 and DAPI. The images were captured by laser scanning confocal microscope $(\mathrm{bar}=10 \mu \mathrm{m}) \mathbf{g}, \mathbf{h}$ The cells were co-transfected with PSMD1-mCherry or PSMD2-mCherry and Livedrop-EGFP vectors for $48 \mathrm{~h}$, and then the cells were treated with $200 \mu \mathrm{M}$ OA for another $6 \mathrm{~h}$. Then, the cells were fixed and stained by BODIPY493/503 and DAPI. The images were captured by a laser scanning confocal microscope (bar $=10 \mu \mathrm{m})$
} 

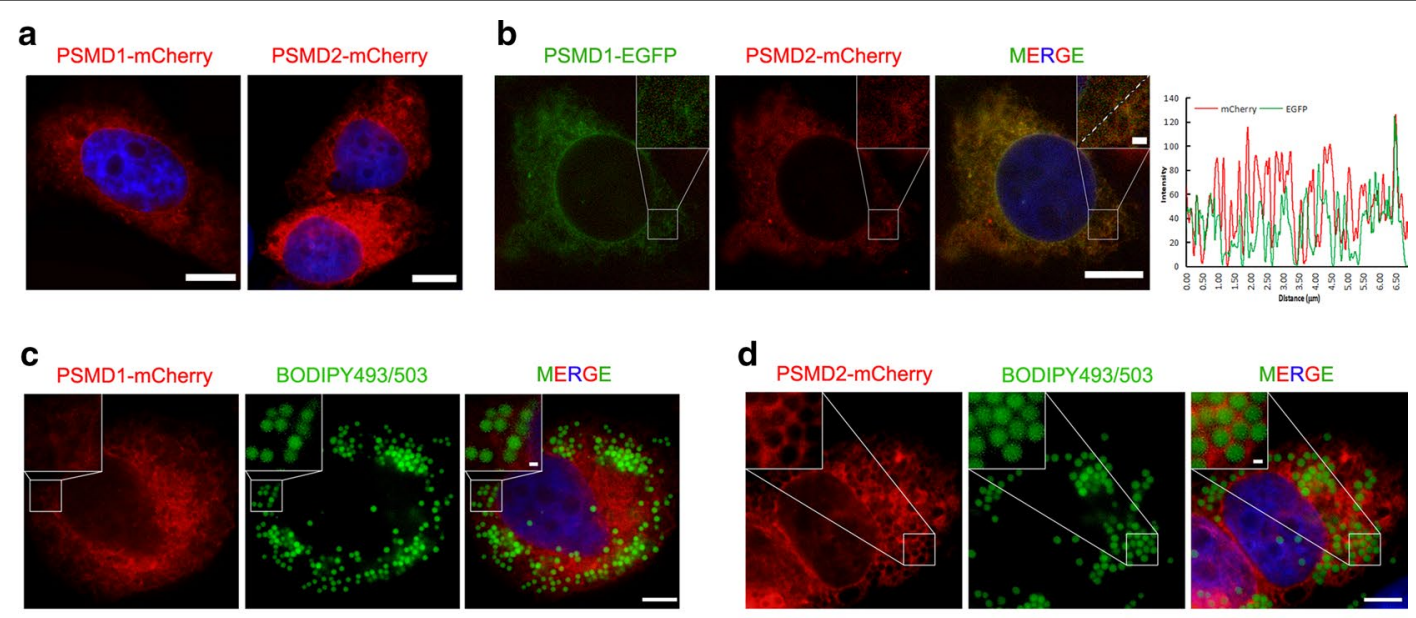

MERGE
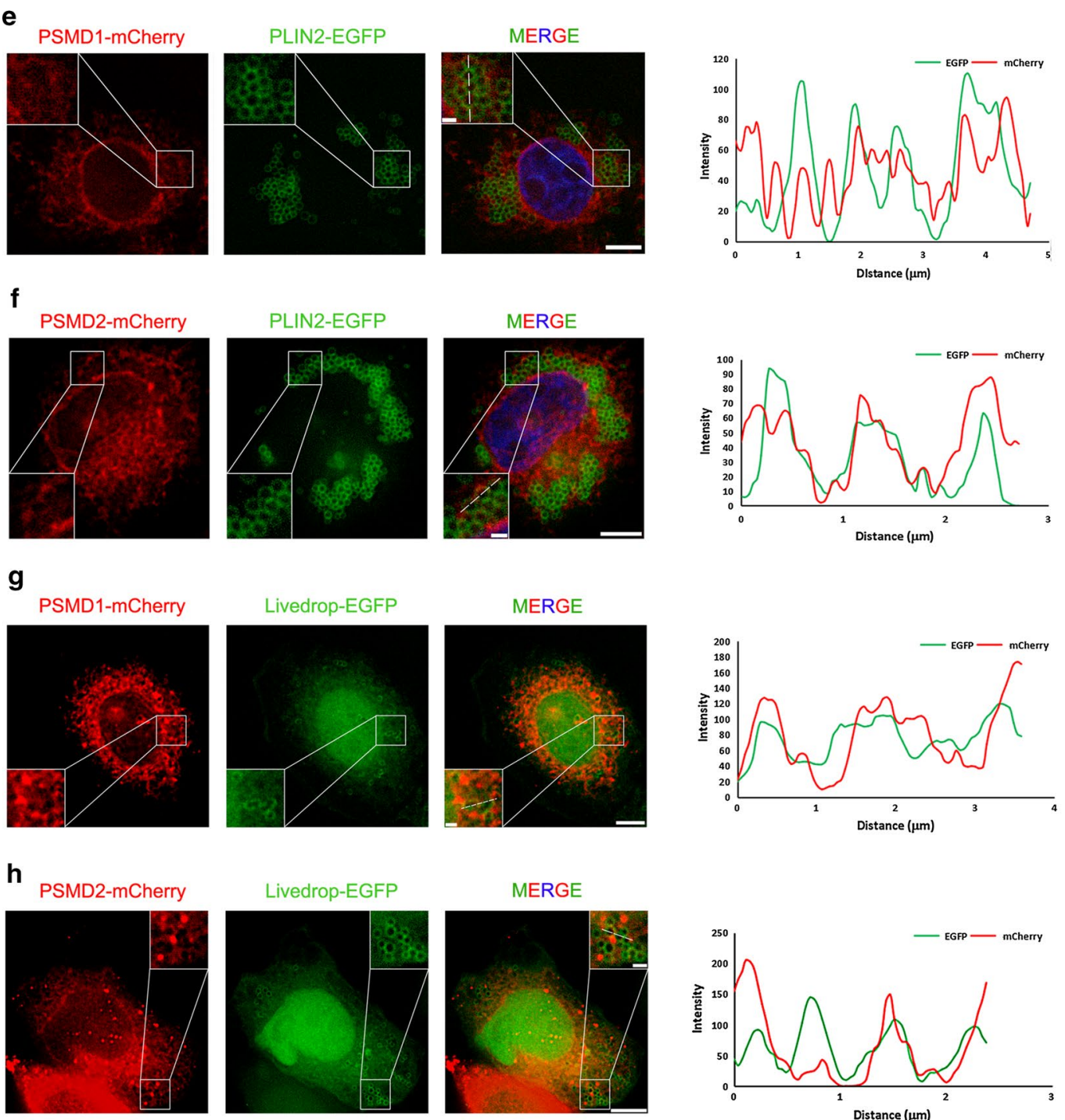

Livedrop-EGFP

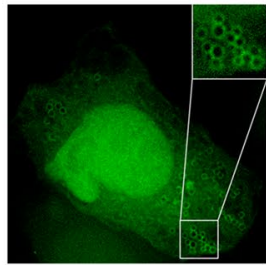

MERGE

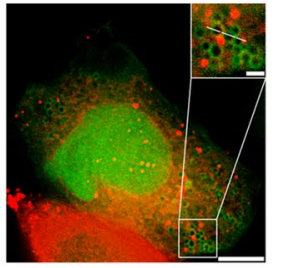

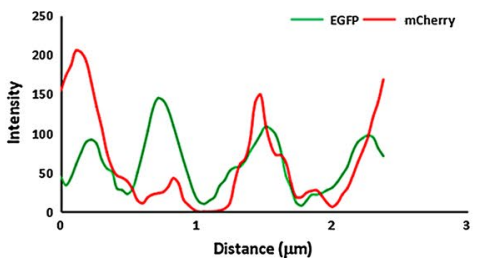


a

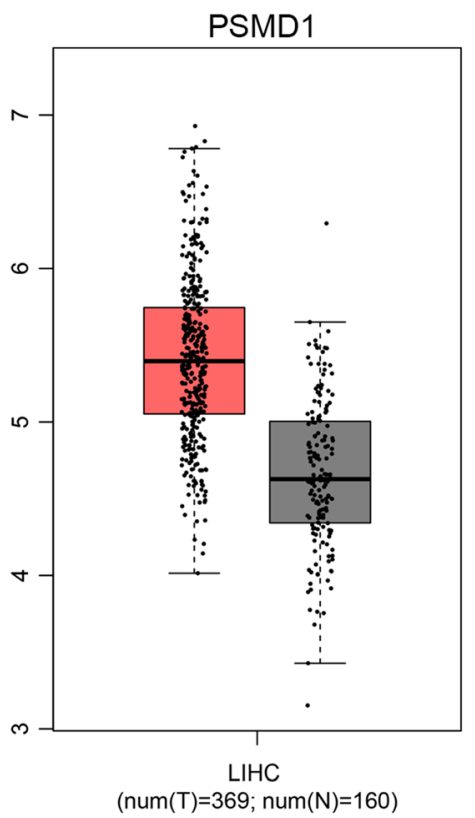

c

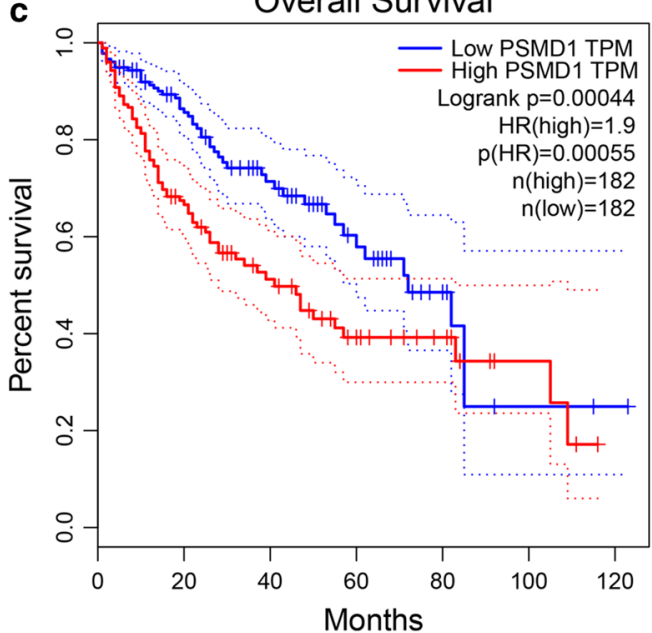

b

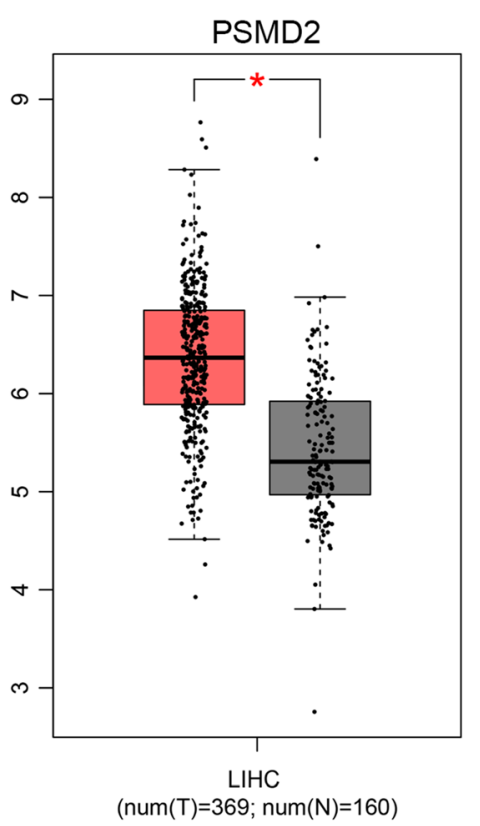

d

Overall Survival

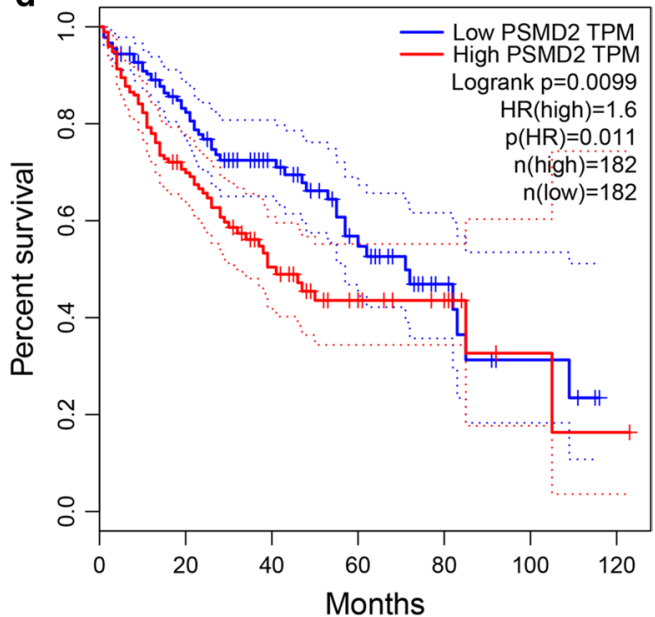

Fig. 8 PSMD1 and PSMD2 show higher expression in liver hepatocellular carcinoma (LIHC) and are associated with a poor prognosis. Gene expression analysis and survival analysis were performed by the GEPIA (gene expression profiling interactive analysis) database (http://gepia.cance r-pku.cn/). a, b Box plot of expression of PSMD1 and PSMD2 in LIHC. c, d The survival analysis of PSMD1 and PSMD2 in LIHC

to the phenotype where the cell-proliferation-related genes were upregulated and cell apoptosis was decreased (Fig. 2). For this phenotype, we considered that PSMD1 and PSMD2 are medium to highly expressed genes, so overexpression might not lead to obvious effects on cellular proliferation, and furthermore, previous studies have reported that the overexpression of PSMD2 could stimulate cell growth $[40,57]$. Therefore, there is no doubt that PSMD1 and PSMD2 could enhance the cell proliferation process. We then tried to validate the idea that PSMD1/PSMD2 regulate cell proliferation via regulating lipid metabolism. Since PSMD1/PSMD2 knockdown downregulated the expression of FA and lipid synthesis genes, we recovered their expression by transfection with SREBF1 or PPARY expression vectors. These two genes are upstream transcriptional factors of FA and lipid synthesis enzymes. The results indicated that cell proliferation was recovered partly when the cells were transfected with SREBF1 or PPARY (Fig. 6), which suggests that this treatment was able to compensate for the impairment of $P S M D 1 / P S M D 2$ knockdown on cell proliferation. We then investigated the co-localization of PSMD1/PSMD2 


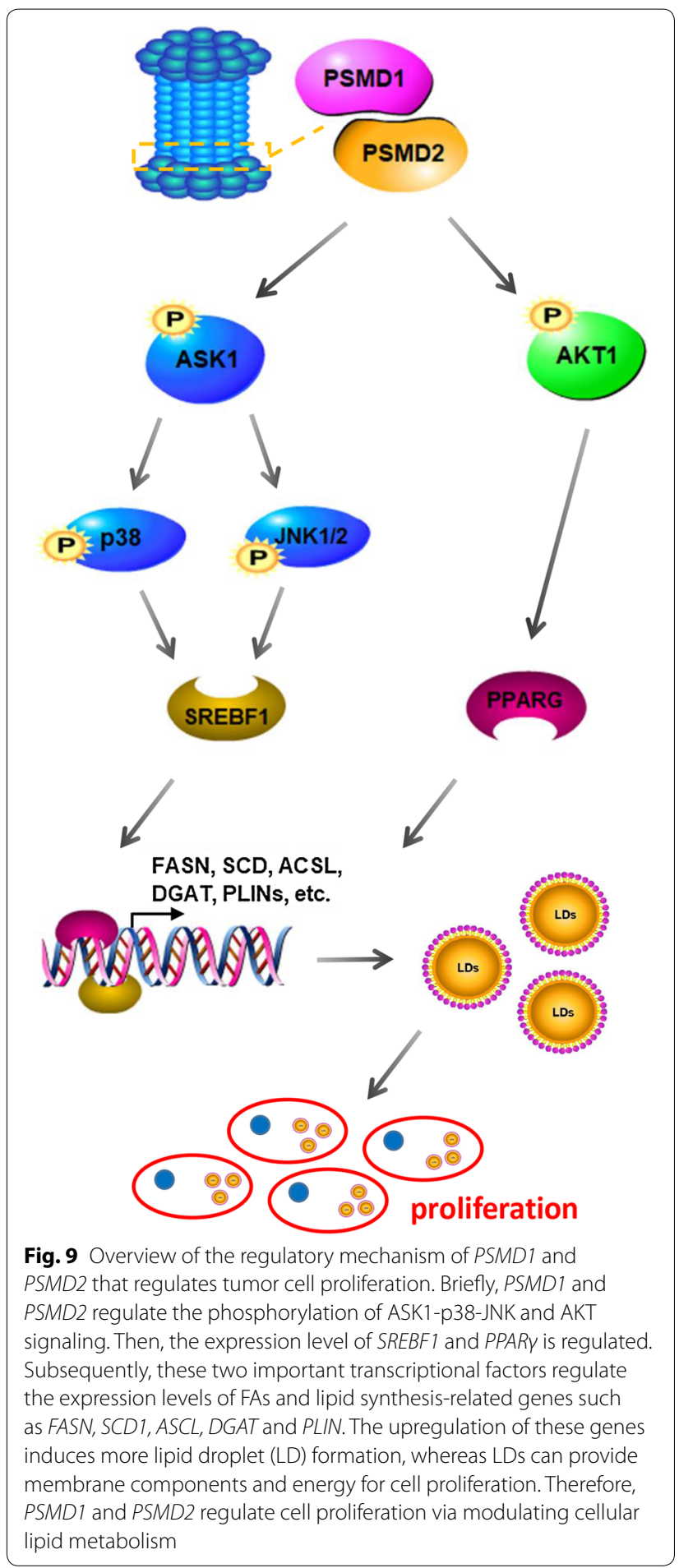

and LDs. Both the mature LDs (labelled by PLIN2-EGFP) and newly formed LDs (labelled by Livedrop-EGFP) were found to be related to the localization of PSMD1 and PSMD2 (Fig. 7f-h), which indicated that PSMD1/PSMD2 were localized to LDs during the generation progression.
Moreover, the localization of PSMD1/PSMD2 on the LD surface suggests that proteasomes might degrade the proteins recruited on LD surfaces. However, the significance of the localization of PSMD1 and PSMD2 on LD surfaces still requires further study. A prognosis analysis was performed to illustrate the association between the PSMD1 and PSMD2 expression levels and survival rates. The results indicated that high expression levels of PSMD1 and PSMD2 decrease the survival rate of LIHC (Fig. 8c, d), which corresponds to our study where PSMD1 and $P S M D 2$ increased the LD content and promoted tumor cell proliferation.

\section{Conclusion}

In the present study, we identified that PSMD1 and PSMD2 could regulate the cellular lipid content, thereby affecting cell proliferation progression. Mechanistically, PSMD1 and PSMD2 regulate FA and lipid synthesis-related gene expression through ASK1-p38JNK and AKT signaling. The molecular mechanism of PSMD1/PSMD2 regulating cell proliferation is illustrated in Fig. 9. This study provides new insights into the PSMD1/PSMD2 regulatory mechanism in HCC cell proliferation and provides a potential novel therapeutic strategy for lipid-rich tumor.

\section{Supplementary information}

Supplementary information accompanies this paper at https://doi. org/10.1186/s12867-019-0141-z.

Additional file 1: Fig. S1. Time course experiment of oleic acid medium treatment. A The cells were treatment with $200 \mu \mathrm{M}$ oleic acid. The cellular lipid droplets were imaged at 1 h, 2 h, 3 h, 4 h, 5 h and 6 h after oleic acid treatment. $\mathbf{B}, \mathbf{C}$ The cell activity of Huh7 cells and HepG2 cells was detected by CCK8 method after $200 \mathrm{mM}$ oleic acid medium treatment for $6 \mathrm{~h}, 12 \mathrm{~h}$ and $24 \mathrm{~h}$.

Additional file 2. Additional tables.

Additional file 3: Fig. S2. PSMD1 and PSMD2 expression level regulates the number and size of cellular lipid droplets in Huh7 cells. The Huh7 cells were seeded on the slide in a 24-well plate. Then, the cells were transfected with PSMD1/PSMD2 or NC siRNAs for $48 \mathrm{~h}$ for knockdown $(\mathbf{A}-\mathbf{C})$, or transfected with PSMD1/PSMD2 expression vector or NC vector for $48 \mathrm{~h}$ for overexpression (D-F). Subsequently, the cells were treated with $200 \mu \mathrm{M}$ oleic acid for another $6 \mathrm{~h}$. Then, the cells were fixed and stained by BODIPY493/503 and DAPI for observation by microscope. (B, E) The number of cellular LDs from different groups of cells. ImageJ software was used for the analysis. The statistical significance of differences between means was assessed using an unpaired Student's t-test $\left(n=20 ;{ }^{*} p<0.05\right.$ ) vs. NC. (C, F) The size of cellular LDs of different groups of cells. ImageJ software was used for the analysis. The statistical significance of differences between means was assessed using an unpaired Student's t-test $\left(n=10 ;{ }^{*} p<0.05 ;\right)$ vs. NC.

\section{Abbreviations}

PSMD1: proteasome 265 subunit, non-ATPase 1; PSMD2: proteasome 265 subunit, non-ATPase 2; UPS: ubiquitin proteasome system; E1: Ub-activating enzyme; E2: Ub-conjugating enzyme; E3: Ub-protein ligase; DUB: deubiquitinating enzyme; PLIN1: perilipin1; PLIN2: perilipin2; PLIN3: perilipin3; PLIN4: 
perilipin4; PLIN5: perilipin5; FSP27/CIDEC: cell death-inducing DFFA-like effector C; SREBF1: sterol regulatory element binding transcription factor 1; PPARY: peroxisome proliferator activated receptor gamma; JNK/MAPK8: mitogenactivated protein kinase 8; OA: oleic acid; SEIPIN/BSCL2: seipin lipid droplet biogenesis associated; FITM1: fat storage inducing transmembrane protein 1 FITM2: fat storage inducing transmembrane protein 2; ATGL/PNPLA2: patatin like phospholipase domain containing 2; CCND1: cyclin D1; CCND2: cyclin D2; CCNB1: cyclin B1; CCNE1: cyclin E1; Ki67: marker of proliferation Ki-67; CASP3: caspase3; CASP8: caspase8; CASP9: caspase9; FAS: Fas cell surface death receptor; FASN: fatty acid synthase; SCD1: stearoyl-CoA desaturase 1; ACSL3: acyl-CoA synthetase long chain family member 3; DGAT1: diacylglycerol O-acyltransferase 1; DGAT2: diacylglycerol O-acyltransferase 2; ASK1/MAP3K5: mitogen-activated protein kinase kinase kinase 5; LIHC: liver hepatocellular carcinoma.

\section{Acknowledgements}

Not applicable.

\section{Authors' contributions}

YJT and ZQR conceived and designed the experiments. YJT performed the experiments. YJT, YJ, and XW analyzed the data and contributed reagents/ materials/analysis tools. YJT wrote the manuscript. ZQR supervised the study. All authors read and approved the final manuscript.

\section{Funding}

This work was supported by the Fundamental Research Funds for the Central Universities (No. 2662018PY043) and the National Project for Breeding of Transgenic Pig (No. 2016ZX08006-002).

\section{Availability of data and materials}

The original data of the real-time PCR experiments, images for western blot analysis, images for fluorescence analysis will be available upon request.

\section{Ethics approval and consent to participate}

No human and animal were involved in the present study. The methods were carried out in accordance with approved guidelines from Huazhong Agricultural University. All of the experimental protocols were subject to approval by the Ethics Committee of Huazhong Agricultural University (HZAUMU2013-0005).

\section{Consent for publication}

This article is distributed under the terms and conditions of the Creative Commons Attribution (CC BY) license (http://creativecommons.org/licenses/ by/4.0/).

\section{Competing interests}

The authors declare that they have no competing interests.

\section{Author details}

${ }^{1}$ Key Laboratory of Swine Genetics and Breeding of Ministry of Agriculture \& Key Laboratory of Agriculture Animal Genetics, Breeding and Reproduction of Ministry of Education, College of Animal Science, Huazhong Agricultural University, Wuhan 430070, Hubei, People's Republic of China. ${ }^{2}$ Bio-Medical Center of Huazhong Agricultural University, Wuhan 430070, Hubei, People's Republic of China.

Received: 1 March 2019 Accepted: 29 October 2019

Published online: 08 November 2019

\section{References}

1. Ferlay J, Soerjomataram I, Dikshit R, Eser S, Mathers C, Rebelo M, Parkin DM, Forman D, Bray F. Cancer incidence and mortality worldwide: sources, methods and major patterns in GLOBOCAN 2012. Int J Cancer. 2015;136(5):E359-86.

2. Nakagawa H, Umemura A, Taniguchi K, Font-Burgada J, Dhar D, Ogata H, Zhong ZY, Valasek MA, Seki E, Hidalgo J, et al. ER stress cooperates with hypernutrition to trigger TNF-dependent spontaneous HCC development. Cancer Cell. 2014;26(3):331-43.
3. Ohki T, Tateishi R, Shiina S, Goto E, Sato T, Nakagawa H, Masuzaki R, Goto T, Hamamura K, Kanai F, et al. Visceral fat accumulation is an independent risk factor for hepatocellular carcinoma recurrence after curative treatment in patients with suspected NASH. Gut. 2009;58(6):839-44.

4. Le TT, Huff TB, Cheng JX. Coherent anti-stokes Raman scattering imaging of lipids in cancer metastasis. BMC Cancer. 2009;9:42.

5. Ramos CV, Taylor HB. Lipid-rich carcinoma of the breast. A clinicopathologic analysis of 13 examples. Cancer. 1974;33(3):812-9.

6. de los Espinosa MA, Hellmén E, Ramírez GA, Herráez P, Rodríguez F, Ordás J, Millán Y, Lara A, de las Martín MJ. Lipid-rich carcinomas of the mammary gland in seven dogs: clinicopathologic and immunohistochemical features. Vet Pathol. 2003;40(6):718-23.

7. Liu Y. Fatty acid oxidation is a dominant bioenergetic pathway in prostate cancer. Prostate Cancer Prostatic Dis. 2006;9(3):230-4.

8. Solomon KR, Pelton K, Freeman MR. The role of cholesterol in prostate cancer. Curr Opin Clin Nutr Metab Care. 2006;9(4):379.

9. Zaytseva YY, Harris JW, Mitov MI, Kim JT, Butterfield DA, Lee EY, Weiss HL, Gao T, Evers BM. Increased expression of fatty acid synthase provides a survival advantage to colorectal cancer cells via upregulation of cellular respiration. Oncotarget. 2015;6(22):18891-904.

10. Peng S, Xia S, Lal B, Shi X, Yang KS, Watkins PA, Laterra J. Lipid metabolism enzyme ACSVL3 supports glioblastoma stem cell maintenance and tumorigenicity. BMC Cancer. 2014;14(1):1-11.

11. Nieman KM, Kenny HA, Penicka CV, Andras L, Rebecca BG, Zillhardt MR, Romero IL, Carey MS, Mills GB, Hotamisligil GKS. Adipocytes promote ovarian cancer metastasis and provide energy for rapid tumor growth. Nat Med. 2011;17(11):1498.

12. Scalfi-Happ C, Udart M, Hauser C, Rück A. Investigation of lipid bodies in a colon carcinoma cell line by confocal Raman microscopy. Med Laser Appl. 2011;26(4):152-7.

13. Antalis CJ, Uchida A, Buhman KK, Siddiqui RA. Migration of MDA-MB-231 breast cancer cells depends on the availability of exogenous lipids and cholesterol esterification. Clin Exp Metastasis. 2011;28(8):733-41.

14. Sanjica R, Tihana DZ, Jasminka S, Marin K, Ozren G, Maja O. FTIR spectroscopy reveals lipid droplets in drug resistant laryngeal carcinoma cells through detection of increased ester vibrational bands intensity. Analyst. 2014;139(13):3407-15.

15. Nieva C, Marro M, Santana-Codina N, Rao S, Petrov D, Sierra A. The lipid phenotype of breast cancer cells characterized by Raman microspectroscopy: towards a stratification of malignancy. PLoS ONE. 2012;7(10):e46456.

16. Walther TC, Chung J, Farese RV. Lipid droplet biogenesis. Annu Rev Cell Dev Biol. 2017;33:491-510.

17. Tirinato L, Pagliari F, Limongi T, Marini M, Falqui A, Seco J, Candeloro P, Liberale C, Di Fabrizio E. An overview of lipid droplets in cancer and cancer stem cells. Stem Cells Int. 2017;2017:1656053.

18. Bickel PE, Tansey JT, Welte MA. PAT proteins, an ancient family of lipid droplet proteins that regulate cellular lipid stores. BBA-Mol Cell Biol Lipids. 2009;1791(6):419-40.

19. Welte M. Expanding roles for lipid droplets. Curr Biol. 2015;25(11):R470-81.

20. Fujimoto T, Ohsaki Y, Cheng J, Suzuki M, Shinohara Y. Lipid droplets: a classic organelle with new outfits. Histochem Cell Biol. 2008;130(2):263-79.

21. Clague MJ, Barsukov I, Coulson JM, Liu H, Rigden DJ, Urbé S. Deubiquitylases from genes to organism. Physiol Rev. 2013;93(3):1289-315.

22. Stewart MD, Ritterhoff T, Klevit RE, Brzovic PS. E2 enzymes: more than just middle men. Cell Res. 2016;26(4):423-40.

23. Wei L, Bengtson MH, Axel U, Akio M, Reddy VA, Anthony O, Chanda SK, Serge B, Joazeiro CAP. Genome-wide and functional annotation of human E3 ubiquitin ligases identifies MULAN, a mitochondrial E3 that regulates the organelle's dynamics and signaling. PLOS ONE. 2008;3(1):e1487.

24. Schulman BA, Harper JW. Ubiquitin-like protein activation by E1 enzymes: the apex for downstream signalling pathways. Nat Rev Mol Cell Biol. 2009;10(5):319-31.

25. Ciechanover A. The ubiquitin-proteasome proteolytic pathway. Cell. 1994;79(1):13.

26. Annamaria M, Michael R. Emerging regulatory mechanisms in ubiquitindependent cell cycle control. J Cell Sci. 2012;125(2):255-63. 
27. Gudmundsdottir K, Lord CJ, Ashworth A. The proteasome is involved in determining differential utilization of double-strand break repair pathways. Oncogene. 2007;26(54):7601-6.

28. He M, Zhou Z, Wu G, Chen Q, Wan Y. Emerging role of DUBs in tumor metastasis and apoptosis: therapeutic implication. Pharmacol Ther. 2017;177:96-107.

29. Daniela H, Ivan D. Targeting the ubiquitin system in cancer therapy. Nature. 2009;458(7237):438.

30. Aparna M, Gelmann EP. The ubiquitin-proteasome pathway and its role in cancer. J Clin Oncol. 2005;23(21):4776-89.

31. Wang J, Maldonado MA. The ubiquitin-proteasome system and its role in inflammatory and autoimmune diseases. Cell Mol Immunol. 2006;3(4):255-61.

32. Adams J. The proteasome: a suitable antineoplastic target. Nat Rev Cancer. 2004;4(5):349-60.

33. Peters J-M, Cejka Z, Harris JR, Kleinschmidt JA, Baumeister W. Structural features of the 26 S proteasome complex. J Mol Biol. 1993;234(4):932-7.

34. Brooks P, Fuertes G, Murray RZ, Bose S, Knecht E, Rechsteiner MC, Hendil KB, Tanaka K, Dyson J, Rivett J. Subcellular localization of proteasomes and their regulatory complexes in mammalian cells. Biochem J. 2000;346(Pt 1):155-61.

35. Gabriel CL, Eric E, Mary EM, Charlene B, Eva N, Andreas M. Complete subunit architecture of the proteasome regulatory particle. Nature. 2012;482(7384):186.

36. Baumeister W, Walz J, Zuhl F, Seemuller E. The proteasome: paradigm of a self-compartmentalizing protease. Cell. 1998;92(3):367-80.

37. Shi Y, Chen X, Elsasser S, Stocks BB, Tian G, Lee BH, Shi Y, Zhang N, de Poot SA, Tuebing F. Rpn 1 provides adjacent receptor sites for substrate binding and deubiquitination by the proteasome. Science. 2016;351(6275):aad9421.

38. Coux O, Tanaka K, Goldberg AL. Structure and functions of the $20 \mathrm{~S}$ and 265 proteasomes. Annu Rev Biochem. 2003;65(1):801-47.

39. Li Y, Huang J, Zeng B, Yang D, Sun J, Yin X, Lu M, Qiu Z, Peng W, Xiang T. PSMD2 regulates breast cancer cell proliferation and cell cycle progression by modulating p21 and p27 proteasomal degradation. Cancer Lett. 2018:430:109-22.

40. Matsuyama Y, Suzuki M, Arima C, Huang QM, Tomida S, Takeuchi T, Sugiyama R, Itoh Y, Yatabe Y, Goto H. Proteasomal non-catalytic subunit PSMD2 as a potential therapeutic target in association with various clinicopathologic features in lung adenocarcinomas. Mol Carcinog. 2015;50(4):301-9.

41. Okumura T, Ikeda K, Ujihira T, Okamoto K, Horie-Inoue K, Takeda S, Inoue S. Proteasome $26 \mathrm{~S}$ subunit PSMD1 regulates breast cancer cell growth through p53 protein degradation. J Biochem. 2017;163(1):19-29.

42. Cermelli S, Guo Y, Gross SP, Welte MA. The lipid-droplet proteome reveals that droplets are a protein-storage depot. Curr Biol. 2006;16(18):1783-95.

43. VrablikTL, Petyuk VA, Larson EM, Smith RD, Watts JL. Lipidomic and proteomic analysis of Caenorhabditis elegans lipid droplets and identification of ACS-4 as a lipid droplet-associated protein. Biochim Biophys Acta. 2015;1851(10):1337-45

44. Khor VK, Ahrends R, Lin Y, Shen WJ, Adams CM, Roseman AN, Cortez Y, Teruel MN, Azhar S, Kraemer FB. The proteome of cholesteryl-esterenriched versus triacylglycerol-enriched lipid droplets. PLOS ONE. 2014;9(8):e105047.

45. Zhang HN, Wang Y, Li J, Yu JH, Pu J, Li LH, Zhang HC, Zhang SY, Peng $\mathrm{G}$, Yang FQ, et al. Proteome of skeletal muscle lipid droplet reveals association with mitochondria and apolipoprotein A-I. J Proteome Res. 2011;10(10):4757-68.

46. Wang WY, Wei SN, Li LH, Su XY, Du CK, Li FJ, Geng B, Liu PS, Xu GH. Proteomic analysis of murine testes lipid droplets. Sci Rep. 2015;5:12070.

47. Khan SA, Wollaston-Hayden EE, Markowski TW, Higgins L, Mashek DG. Quantitative analysis of the murine lipid droplet-associated proteome during diet-induced hepatic steatosis. J Lipid Res. 2015;56(12):2260-72.

48. Rosch K, Kwiatkowski M, Hofmann S, Schobel A, Gruttner C, Wurlitzer M, Schluter H, Herker E. Quantitative lipid droplet proteome analysis identifies annexin A3 as a cofactor for HCV particle production. Cell Rep. 2016;16(12):3219-31.

49. Kaneko T, Hamazaki J, lemura S, Sasaki K, Furuyama K, Natsume T, Tanaka K, Murata S. Assembly pathway of the mammalian proteasome base subcomplex is mediated by multiple specific chaperones. Cell. 2009;137(5):914-25
50. Costantini S, Di Bernardo G, Cammarota M, Castello G Colonna G. Gene expression signature of human HepG2 cell line. Gene. 2013;518(2):335-45

51. LvY, Jin $Y, Z$ hou $Y$, Jin J, Ma Z, Ren Z. Deep sequencing of transcriptome profiling of GSTM2 knock-down in swine testis cells. Sci Rep. 2016;6:38254.

52. Wang H, Becuwe M, Housden BE, Chitraju C, Porras AJ, Graham MM, Liu XN, Thiam AR, Savage DB, Agarwal AK. Seipin is required for converting nascent to mature lipid droplets. Elife. 2016:5:e16582.

53. Tang Z, Li C, Kang B, Gao G, Li C, Zhang Z. GEPIA: a web server for cancer and normal gene expression profiling and interactive analyses. Nucleic Acids Res. 2017:45(Web Server issue):W98-102.

54. Sunwoo J, Chen Z, Dong G, Yeh N, Crowl-Bancroft C, Sausville E, Adams J, Elliott P, Van-Waes C. Novel proteasome inhibitor PS-341 inhibits activation of nuclear factor-kappa B, cell survival, tumor growth, and angiogenesis in squamous cell carcinoma. Clin Cancer Res. 2001;7(5):1419-28.

55. Orlowski RZ, Eswara JR, Lafond-Walker A, Grever MR, Orlowski M, Dang CV. Tumor growth inhibition induced in a murine model of human Burkitt's lymphoma by a proteasome inhibitor. Can Res. 1998;58(19):4342-8.

56. Tomida S, Yanagisawa K, Koshikawa K, Yatabe Y, Mitsudomi T, Osada H, Takahashi T. Identification of a metastasis signature and the DLX4 homeobox protein as a regulator of metastasis by combined transcriptome approach. Oncogene. 2007;26(31):4600-8.

57. Wan D, Gong Y, Qin W, Zhang P, Li J, Wei L, Zhou X, Li H, Qiu X, Zhong F. Large-scale cDNA transfection screening for genes related to cancer development and progression. Proc Natl Acad Sci USA. 2004;101(44):15724-9.

58. Wilfling F, Haas JT, Walther TC, Farese RV Jr. Lipid droplet biogenesis. Curr Opin Cell Biol. 2014;29(1):39-45.

59. Welte MA, Gould AP. Lipid droplet functions beyond energy storage. Biochem Biophys Acta. 2017;1862(10):1260-72.

60. Randall G. Lipid droplet metabolism during dengue virus infection. Trends Microbiol. 2018;26:640-2.

61. Zhang C, Liu P. The lipid droplet: a conserved cellular organelle. Protein Cell. 2017:8(11):796-800.

62. Gluchowski NL, Becuwe M, Walther TC, Farese RV Jr. Lipid droplets and liver disease: from basic biology to clinical implications. Nat Rev Gastroenterol Hepatol. 2017;14(6):343-55.

63. Tirinato L, Pagliari F, Limongi T, Marini M, Falqui A, Seco J, Candeloro $P_{\text {, }}$ Liberale C, Di FE. An overview of lipid droplets in cancer and cancer stem cells. Stem Cells Int. 2017;2017(3):1-17.

64. Aboumrad MH, Horn RC Jr, Fine G. Lipid-secreting mammary carcinoma. Report of a case associated with Paget's disease of the nipple. Cancer. 1963;16(4):521-5.

65. Le TT, Huff TB, Cheng JX. Coherent anti-stokes Raman scattering imaging of lipids in cancer metastasis. BMC Cancer. 2009;9(1):42.

66. Fujimoto T, Kogo H, Ishiguro K, Tauchi K, Nomura R. Caveolin-2 is targeted to lipid droplets, a new "membrane domain" in the cell. J Cell Biol. 2001;152(5):1079-85.

67. Yu W, Bozza PT, Tzizik DM, Gray JP, Cassara J, Dvorak AM, Weller PF. Co-compartmentalization of MAP kinases and cytosolic phospholipase A2 at cytoplasmic arachidonate-rich lipid bodies. Am J Pathol. 1998;152(3):759-69.

68. Yu W, Cassara J, Weller PF. Phosphatidylinositide 3-kinase localizes to cytoplasmic lipid bodies in human polymorphonuclear leukocytes and other myeloid-derived cells. Blood. 2000;95(3):1078.

69. Salem Ait K, Marc-Alexandre E-B, Danielle C, Véronique C, Michel L, Monique R, Sylvie D, Etienne M. Autophagosomes contribute to intracellular lipid distribution in enterocytes. Mol Biol Cell. 2014;25(1):118-32.

70. Albert H, Marta B, Nicholas A, Reddy BJN, Alba F, Andrea FV, Anna AG, Manuel Alejandro FR, Carles R, Francesc T. Cell-to-cell heterogeneity in lipid droplets suggests a mechanism to reduce lipotoxicity. Curr Biol. 2013;23(15):1489-96.

71. Penrose H, Heller S, Cable C, Makboul R, Chadalawada G, Chen Y, Crawford SE, Savkovic SD. Epidermal growth factor receptor mediated proliferation depends on increased lipid droplet density regulated via a negative regulatory loop with FOXO3/Sirtuin6. Biochem Biophys Res Commun. 2016:469(3):370-6.

72. Shpilka T, Elazar Z. Lipid droplets regulate autophagosome biogenesis. Autophagy. 2015;11(11):2130-1. 
73. Luca T, Carlo L, Simone DF, Patrizio C, Antonina B, Rosanna LR, Lisette P, Roberto M, Roberta R, Rajamanickam VP. Lipid droplets: a new player in colorectal cancer stem cells unveiled by spectroscopic imaging. Stem Cells. 2015;33(1):35-44.

74. Eileen $\mathbf{W}$. The role for autophagy in cancer. J Clin Investig. 2015;125(1):42-6.

75. Guoheng X, Carole S, Xinyue L, Tansey JT, Jaiwei G, Heidi D, Kimmel AR, Constantine L. Post-translational regulation of adipose differentiationrelated protein by the ubiquitin/proteasome pathway. J Biol Chem. 2005;280(52):42841-7.

76. Masuda Y, Itabe H, Odaki M, Hama K, Fujimoto Y, Mori M, Sasabe N, Aoki J, Arai H, Takano T. ADRP/adipophilin is degraded through the proteasomedependent pathway during regression of lipid-storing cells. J Lipid Res. 2006;47(1):87

77. Ruggiano A, Mora G, Buxó L, Carvalho P. Spatial control of lipid droplet proteins by the ERAD ubiquitin ligase Doa10. EMBO J. 2016;35(15):1644-55.

78. Eastman SW, Yassaee M, Bieniasz PD. A role for ubiquitin ligases and Spartin/SPG20 in lipid droplet turnover. J Cell Biol. 2009;184(6):881-94.

79. Yoshizawa T, Karim MF, Sato Y, Senokuchi T, Miyata K, Fukuda T, Go C, Tasaki M, Uchimura K, Kadomatsu T. SIRT7 controls hepatic lipid metabolism by regulating the ubiquitin-proteasome pathway. Cell Metab. 2014;19(4):712-21.

80. Guo Y, Walther TC, Rao M, Stuurman N, Goshima G, Terayama K, Wong JS, Vale RD, Walter P, Farese RV Jr. Functional genomic screen reveals genes involved in lipid-droplet formation and utilization. Nature. 2008;453(7195):657-61.

81. Zhang P, Wang PX, Zhao LP, Zhang X, Ji YX, Zhang XJ, Fang C, Lu YX, Yang $X$, Gao MM. The deubiquitinating enzyme TNFAIP3 mediates inactivation of hepatic ASK1 and ameliorates nonalcoholic steatohepatitis. Nat Med. 2017;24(1):84

82. Liu L, Zhang K, Sandoval H, Yamamoto S, Jaiswal M, Sanz E, Li Z, Hui J, Graham B, Quintana A. Glial lipid droplets and ROS induced by mitochondrial defects promote neurodegeneration. Cell. 2015;160(1-2):177-90.

83. Yongsheng C, Jieru W, Xiaojun L, Thewke DP, Mason RJ. KGF induces lipogenic genes through a PI3K and JNK/SREBP-1 pathway in H292 cells. J Lipid Res. 2005;46(12):2624-35.

84. Minoru I, Michiaki N, Naoki O, Masaki T, Junichi I, Tomohiro I, Yunike A, Koji M. A novel JNK2/SREBP-1C pathway involved in insulin-induced fatty acid synthesis in human adipocytes. J Lipid Res. 2013;54(6):1531.
85. Knebel B, Lehr S, Hartwig S, Haas J, Kaber G, Dicken HD, Susanto F, Bohne $L$, Jacob S, Nitzgen U. Phosphorylation of sterol regulatory elementbinding protein (SREBP)-1c by p38 kinases, ERK and JNK influences lipid metabolism and the secretome of human liver cell line HepG2. Archives Internationales De Physiologie. 2014;120(5):216-27.

86. Szabolcs F, Lynda E, Norman B, Corentin C-M, Irina K, Hiroaki K, Ernesto B-M. Akt induces beta-cell proliferation by regulating cyclin D1, cyclin D2, and p21 levels and cyclin-dependent kinase-4 activity. Diabetes. 2006;55(2):318-25.

87. Eddy SF, Storey KB. Differential expression of Akt, PPARgamma, and PGC-1 during hibernation in bats. Biochem Cell Biol. 2003;81(4):269-74.

88. Hartmann W, DigonSöntgerath B, Koch A, Waha A, Endl E, Dani I, Denkhaus D, Goodyer CG, Sörensen N, Wiestler OD. Phosphatidylinositol 3'-kinase/AKT signaling is activated in medulloblastoma cell proliferation and is associated with reduced expression of PTEN. Clin Cancer Res. 2006;12(10):3019-27.

89. Lawlor MA, Alessi DR. PKB/Akt: a key mediator of cell proliferation, survival and insulin responses? J Cell Sci. 2001;114(16):2903-10.

90. Shimon R, Alon L, Lindquist JN, Yutaka Y, Erwin G, Andrew S, Brenner DA, Rippe RA. The role of focal adhesion kinase-phosphatidylinositol 3-kinase-akt signaling in hepatic stellate cell proliferation and type I collagen expression. J Biol Chem. 2003;278(10):8083-90.

91. Pene F, Claessens YE, Muller O, Viguie F, Mayeux P, Dreyfus F, Lacombe C, Bouscary D. Role of the phosphatidylinositol 3-kinase/Akt and mTOR/ P70S6-kinase pathways in the proliferation and apoptosis in multiple myeloma. Oncogene. 2002;21(43):6587-97.

92. Tsurutani J, Castillo SS, Brognard J, Granville CA, Zhang C, Gills JJ, Sayyah J, Dennis PA. Tobacco components stimulate Akt-dependent proliferation and NFKB-dependent survival in lung cancer cells. Carcinogenesis. 2005;26(7):1182-95.

93. Peltier J, O'Neill A, Schaffer DV. PI3 K/Akt and CREB regulate adult neural hippocampal progenitor proliferation and differentiation. Dev Neurobiol. 2007;67(10):1348-61.

\section{Publisher's Note}

Springer Nature remains neutral with regard to jurisdictional claims in published maps and institutional affiliations.
Ready to submit your research? Choose BMC and benefit from:

- fast, convenient online submission

- thorough peer review by experienced researchers in your field

- rapid publication on acceptance

- support for research data, including large and complex data types

- gold Open Access which fosters wider collaboration and increased citations

- maximum visibility for your research: over $100 \mathrm{M}$ website views per year

At BMC, research is always in progress.

Learn more biomedcentral.com/submissions 